\title{
Environmental controls on pyrocumulus and pyrocumulonimbus initiation and development
}

\author{
Neil P. Lareau and Craig B. Clements
}

Fire Weather Research Laboratory, Department of Meteorology and Climate Science, San José State University, San Jose, California, USA

Correspondence to: Neil P. Lareau (neil.lareau@sjsu.edu)

Received: 21 September 2015 - Published in Atmos. Chem. Phys. Discuss.: 27 October 2015

Revised: 17 February 2016 - Accepted: 3 March 2016 - Published: 29 March 2016

\begin{abstract}
In this paper we present the first direct observational evidence that the condensation level in pyrocumulus and pyrocumulonimbus clouds can be significantly higher than the ambient lifted condensation level. In addition, we show that the environmental thermodynamic profile, day-today variations in humidity, and ambient wind shear all exert significant influence over the onset and development of pyroconvective clouds. These findings are established using a scanning Doppler lidar and mobile radiosonde system during two large wildfires in northern California, the Bald Fire and the Rocky Fire. The lidar is used to distinguish liquid water from smoke backscatter during the plume rise, and thus provides a direct detection of plume condensations levels. Plume tops are subsequently determined from both the lidar and nearby radar observations. The radiosonde data, obtained adjacent to the fires, contextualize the lidar and radar observations, and enable estimates of the plume ascent, convective available potential energy, and equilibrium level. A noteworthy finding is that in these cases, the convective condensation level, not the lifted condensation level, provides the best estimate of the pyrocumulus initiation height.
\end{abstract}

\section{Introduction}

Pyrocumulus clouds (pyroCus) form when wildfire convective plumes rise to their condensation level and subsequently develop cumuliform cloud tops (American Meteorological Society, 2015a). The extent of pyroCu development depends on the relationships amongst atmospheric stratification, ambient moisture, and fire fluxes of heat and moisture (Potter, 2005; Luderer et al., 2006, 2009; Freitas et al., 2007).
Some pyroCus release significant moist instability aloft and thereby trigger deep convective clouds that sometimes grow into pyrocumulonimbus clouds (pyroCbs). Compared to their lesser counterparts, pyroCbs possess glaciated cloud tops and can thus generate precipitation, downdrafts, and lightning (American Meteorological Society, 2015b). In exceptional cases, pyroCbs have been linked with extreme fire growth (Peterson et al., 2015), devastating firestorms (Fromm et al., 2006), and even fire-induced tornados (Cunningham and Reeder, 2009; McRae et al., 2013).

In addition to their impact on fire behavior, pyroCus/Cbs have garnered significant research attention due to their affect on vertical smoke transport, atmospheric chemistry, and cloud microphysics. For example, pyroCus can cause significantly deeper smoke injection than is caused in dry convective cases (Frietas et al., 2007), and pyroCb clouds are now recognized as the source of previously unexplained aerosol layers lofted in the lower stratosphere (Fromm and Servranckx, 2003; Fromm et al., 2006, 2010). In addition, satellite and dual polarimetric radar observations of pyroCb show that the extreme aerosol loading results in high concentrations of small ice particles (Rosenfeld et al., 2007), especially as compared to nearby clouds forming in smoke free air. The abundance of ice particles changes the radiative properties of the clouds and also favors atypical positive polarity lightning strokes (Rosenfeld et al., 2007; Lang et al., 2006, 2014).

Despite the significant research on pyroCu/Cb microphysics, surprisingly little is known about the environmental controls on pyroCu development. To date, only a handful of studies explicitly examines the thermodynamic and kinematic structure of these cloud-topped convective columns 
(Potter, 2005; Trentman et al., 2006; Luderer et al., 2006, 2009; Freitas et al., 2007) and no studies include direct observations of pyroCu/Cb initiation. As a result, there is an open scientific debate regarding the plume condensation level, which is an important parameter for modeling smoke injection height and plume evolution (Freitas et al., 2007). Specifically, there are contrasting views in the literature about whether the plume condensation level is expected to be higher than or lower than the ambient lifted condensation level (LCL).

Potter (2005), for example, proposes that pyroCus/Cbs should exhibit cloud bases lower than the ambient LCL due to the moisture released during combustion of woody fuels and from the evaporation of fuel moisture. Drawing on historical cases of pyroCus/Cbs, radiosonde data, and theoretical considerations, he hypothesizes that the latent heat release may be the dominant factor in many moistpyroconvective events. A limitation of this study is the anecdotal treatment of condensation levels, which are estimated, and the use of radiosonde observations that may not reflect the near fire environment.

In contrast to Potter (2005), Luderer et al. (2006, 2009) use high-resolution simulations and theoretical sensitivity calculations to conclude that "the combined effect of released moisture and heat from the fire almost always results in a higher cloud base compared to ambient conditions." They also find that moisture released in combustion constitutes less than $10 \%$ of the pyro $\mathrm{Cu} / \mathrm{Cb}$ water budget with the remainder of the plume water resulting from entrained environmental air. While these modeled results are rather convincing, they lack clear observational support.

To that end, the only field observations that address plume moisture are from small-scale grass fire experiments, where significant increases in water vapor mixing ratio are documented near the surface, but then decrease rapidly with height (Clements et al., 2006, 2007; Kiefer et al., 2012). While these observations are consistent with the dominant role of entrainment, such small-scale plumes may not be representative of deep convective plumes that extend into the upper troposphere or even lower stratosphere.

In this paper we present the first direct observations of condensation levels in two wildfire pyroCu/Cb cases. The fires, the Bald Fire and the Rocky Fire, were located in northern California, and observations were conducted on $2 \mathrm{Au}-$ gust 2014 and 30 July 2015, respectively (Fig. 1). The pyroCu cloud bases and plume rise dynamics were measured using a mobile atmospheric profiling system (Clements and Oliphant, 2014) that included a scanning Doppler lidar and an upper-air radiosonde system which provided thermodynamic profiles immediately upstream of the fire perimeters. From these data, our results clearly show that observed plume condensation levels are substantially higher than the ambient LCL. Additional aspects of the plume rise, including limiting factors on convective growth and the role of environmental moisture are also examined.

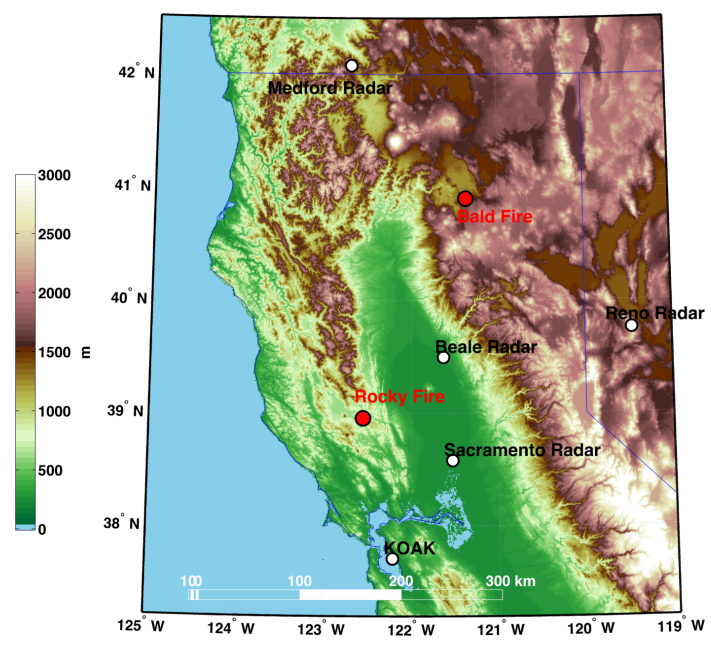

Figure 1. Overview map showing the regional topography (terrain shading), locations of the Rocky Fire and the Bald Fire (red circles), the locations and names of the NWS radars used in the plume analysis (white circles), and the KOAK sounding site (white circle).

\section{Data and methods}

\subsection{Lidar data}

In this study, data from a Halo Photonics scanning Doppler lidar are examined (Pearson et al., 2009). The lidar emits a $1.5 \mu \mathrm{m}$ laser beam and records two range-resolved quantities: (1) the attenuated backscatter coefficient $\left(\mathrm{m}^{-1} \mathrm{sr}^{-1}\right)$, which is a range corrected measure of backscattered energy, and (2) the Doppler velocity $\left(\mathrm{m} \mathrm{s}^{-1}\right)$. The lidar also reports the signal-to-noise ratio (SNR), which is useful for discriminating between meteorological targets and instrument noise. The lidar range is $9.6 \mathrm{~km}$ and the range-gate resolution is $18 \mathrm{~m}$. Azimuth and elevation motors allow for scans of the full upper hemisphere and the lidar is level-mounted to the bed of a pickup truck, enabling rapid deployments to wildfires (Clements and Oliphant, 2014).

\subsubsection{Lidar sensitivity}

Near-IR lidars are sensitive to aerosol, cloud droplets, and forest fire smoke. Due to these sensitivities numerous previous studies have used lidars to examine smoke layers and smoke plumes (Banta et al., 1992; Kovalev et al., 2005; Pahlow et al., 2005; Charland and Clements, 2013; Lareau and Clements, 2015).

Forest fire smoke typically exhibits a log-normal particle number distribution with a peak near $0.13 \mu \mathrm{m}$ and a long tail extending towards coarser particles (Radke et al., 1990, 1991; Banta et al., 1992; Reid and Hobbs, 1998; Reid et al., 2005). The corresponding mass distributions are bimodal with peaks near 0.1 and $10 \mu \mathrm{m}$ and a local minimum between 1 and $3 \mu \mathrm{m}$ (Radke et al., 1990, 1991; Reid et al., 2005). During intense forest fires, such as those in this study, 
additional "super-giant" aerosol with sizes sometimes exceeding $1 \mathrm{~mm}$ may also be prevalent (Radke et al., 1990, 1991; Reid et al., 2005). These aerosols are typically composed of large ash and soil particles, which may be scoured from the surface by strong fire-induced winds (Radke et al., 1991; Reid et al., 2005; Kavouras et al., 2012).

The $1.5 \mu \mathrm{m}$ lidar beam interacts with the submicron smoke via Rayleigh scattering, the micron-sized smoke via Mie scattering, and with the coarsest aerosol (e.g., large ash, debris, etc.) via geometric optics. Using a radiative transfer model, Banta et al. (1992) showed that the attenuated backscatter coefficient due to the numerous small smoke particles was roughly comparable to the backscatter from the sparse large particles in a given volume. Similar behavior is expected with the lidar used in this study. In addition, based on our own experience, we expect significant attenuation for interactions with very coarse debris, especially near the base of smoke plumes.

Near-IR lidars also record high backscatter and rapid attenuation due to cloud droplets, making them an ideal tool for cloud base and cloud top detections (Hogan et al., 2003; Winker et al., 2009). In this study we leverage this attribute of the lidar to determine pyroCu cloud bases and edges in the convective column. Similarly, Banta et al. (1992) used an IR lidar to identify pyroclouds in a wildfire smoke column.

\subsubsection{Lidar scan strategy}

The lidar was programmed to conduct "range-height indicator" (RHI) scans centered on the Bald Fire and Rocky Fire pyroconvective plumes. The scan azimuth angles were determined visually. During the Bald Fire, the RHI elevation step was $0.7^{\circ}$, whereas an elevation step of $1^{\circ}$ was used during the Rocky Fire. Scans were conducted between the horizon and $\sim 85^{\circ}$ in elevation, with a full RHI sweep taking $\sim 1 \mathrm{~min}$ during the Bald Fire and $\sim 45 \mathrm{~s}$ during the Rocky Fire. Additional scan details, including the azimuth angles, are provided in the following case studies.

The lidar was also used to examine the velocity field near the fires and within the convective plumes. For example, the Doppler radial velocity data collected during the RHI scans are used to inspect the plume structure. These data have a resolution of $3-4 \mathrm{~cm} \mathrm{~s}^{-1}$ over a range of $\pm 19 \mathrm{~m} \mathrm{~s}^{-1}$ (Pearson et al., 2009). In addition, conical scans were interspersed with RHI scans to generate vertical profiles of the horizontal wind using the "velocity-azimuth display" (VAD) technique (Browning and Wexler, 1968). The VADs use an elevation angle of $50^{\circ}$ and span $360^{\circ}$ in azimuth, taking about $1 \mathrm{~min}$ to complete. The post-processed wind speed and direction from the VADs reflect the ambient winds above the lidar.

\subsubsection{Plume edge detection}

The lidar data are post-processed to determine plume boundaries and beam attenuation depth. The edge detection al-
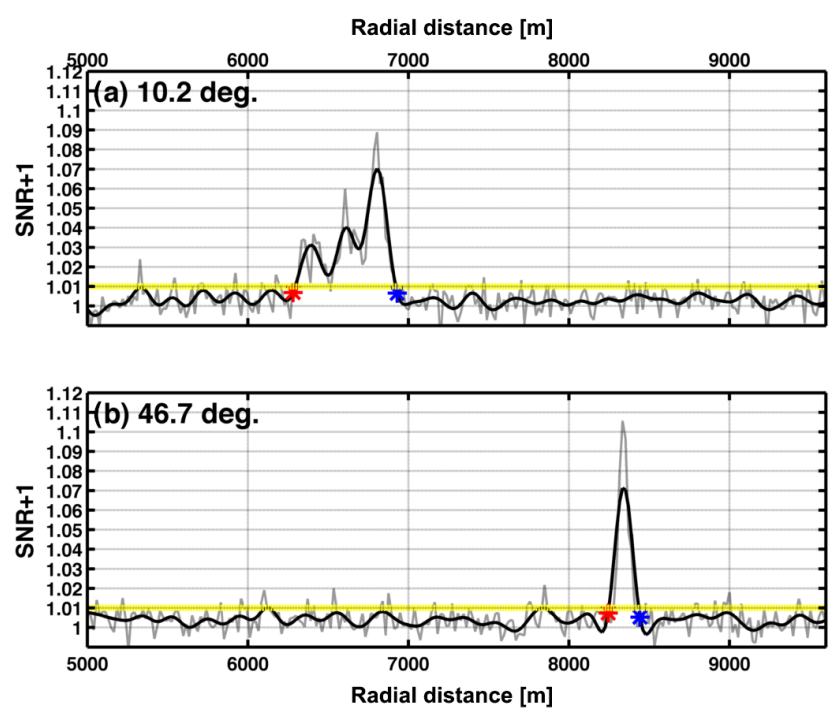

Figure 2. Examples of the plume detection and attenuation algorithm based on the filtered (solid black line) and unfiltered (gray line) lidar signal-to-noise ratio $(\mathrm{SNR}+1)$. (a) Low elevation angle $\left(10.2^{\circ}\right)$ lidar beam intersecting the base of the Bald Fire convective column. (b) High elevation angle $\left(46.7^{\circ}\right)$ beam intersecting the pyroCu in the upper plume. The red stars indicate the leading plume edge and the blue stars the attenuation point. The SNR +1 threshold of 1.01 is indicated with a dashed yellow line.

gorithm uses a combination of the lidar signal-to-noise ratio (SNR) and attenuated backscatter coefficient to isolate the plume. Similar approaches are presented in previous studies (Kovalelv et al., 2005; Charland and Clements, 2013). In our analysis, we first apply a 5th order Butterworth filter with a 5-point window to the SNR data along each lidar beam to eliminate some of the instrument noise. Next we record the radial location of maximum attenuated backscatter coefficient. Starting from that location we search inward along the beam for the first range gate where the SNR +1 drops below 1.01. This point is considered to be the leading plume edge. The same technique is performed searching outward along the beam to find the trailing plume edge. The trailing edge is considered to be the attenuation point provided the $\mathrm{SNR}+1$ does not again exceed the threshold at some further distance. The SNR +1 threshold of 1.01 was found to best discriminate between aerosol returns and background noise in our data sets, though other values (e.g., SNR $+1=1.02$ ) provide similar results.

To demonstrate the algorithm, Fig. 2 presents lidar data extracted from two elevation angles $\left(10.2,46.7^{\circ}\right)$ within a full RHI scan of Bald Fire convective column. The lower elevations beam (Fig. 2a) intersects the base of the smoke plume while the upper beam (Fig. 2b) hits the pyroCu. Of note, the SNR +1 associated with cloud is somewhat higher than in the smoke (1.105 vs. 1.089) and beam's attenuation is much more rapid, penetrating only $198 \mathrm{~m}$ into the cloud compared to $648 \mathrm{~m}$ into the smoke. In the following case studies we 
show that the sudden reduction in attenuation depth and increase in attenuated backscatter coefficient aloft are robust signatures of pyroCu formation.

\subsection{Radar data}

Data from four National Weather Service (NWS) radars are used to examine plume structure. These $10 \mathrm{~cm}$ radars are sensitive to large ash and precipitation particles in the convective column but insensitive to cloud droplets and sub-micron smoke. Radars have been used in numerous wildfires studies (Banta et al., 1992; Hufford et al., 1998; Fromm et al., 2006; Rosenfeld et al., 2007; Jones and Christopher, 2010a, b). Recently, dual-polarization radars have been used to examine the microphysics of wildfire plumes and clouds (Melnikov et al., 2008, 2009; Lang et al., 2014).

In this study we leverage three aspects of the NWS radars. First we examine the radar echo tops to estimate the maximum cloud height. The echo tops are the highest level at which the radar reflectivity exceeds $18 \mathrm{dbZ}$ (Lakshmanan et al., 2013). Second we combine radar reflectivity from multiple radars to generate volume renderings of the pyroconvective plumes. These volumes are constructed by creating a gridded interpolant from all the available contemporaneous radar data. Data from the Medford, Reno, Beale, and Sacramento radars are combined for the Bald Fire, and from the Beale and Sacramento radars for the Rocky Fire. The radar locations relative to the fires are shown in Fig. 1.

Finally, we inspect the differential reflectivity $\left(Z_{\mathrm{dr}}\right)$ data from the Medford, OR radar during the Bald Fire. $Z_{\mathrm{dr}}$ is the logarithmic ratio of the reflectivity from the horizontally and vertically polarized radar beams (Markowski and Richardson, 2011). When $Z_{\mathrm{dr}}$ is large and positive it indicates the presence of large horizontal targets, including needle-like ash particles (Melnikov et al., 2008, 2009). When $Z_{\mathrm{dr}}$ is near zero the targets are more spherical (e.g., hydrometeors), and when negative the targets are vertically oriented (e.g., graupel).

\subsection{Satellite data}

Visible satellite observations from the Geostationary Operational Environmental Satellite (GOES-15) are used to characterize the presence of pyroCus above each fire. These data have a spatial resolution of $1 \mathrm{~km}$ and a nominal temporal resolution of $15 \mathrm{~min}$, depending on the scan schedule. Data from the Moderate Resolution Imaging Spectroradiometer (MODIS) Terra and Aqua satellites are also used. These data include both true color visible images and fireradiative power (FRP). The nominal resolution is $500 \mathrm{~m}$. FRP is derived by differencing fire pixels from adjacent non-fire pixels using infrared radiance (Wooster, 2002) and has been shown to provide high fidelity representation of fire activity during California wildfires (Koltunov et al., 2012; Peterson et al., 2015). FRP data from GOES are also examined.

\subsection{Radiosonde observation and analysis}

Thermodynamic profiles were collected adjacent to both fires using a GRAW ${ }^{\mathrm{TM}}$ GS-E radiosonde system. These sondes measure temperature, humidity, and wind from the surface to the tropopause, ascending at a rate of $\sim 3 \mathrm{~m} \mathrm{~s}^{-1}$. The balloons were launched after sunset to avoid interfering with daytime fire-suppression aircraft operations, and as a result the temperature profiles include surface-based stable layers that are not representative of daytime conditions. To address this shortcoming, the afternoon temperature from the truck weather station is used to infer the convective boundary layer (CBL) depth using the "parcel method" (Holtzworth, 1964).

The sonde data are used to examine the ambient condensation level by considering three lifted parcels (1) the most unstable (MU) parcel, (2) the mixed-layer (ML) parcel, and (3) the convective (CONV) parcel. The MU parcel is the parcel with the highest convective available potential energy (CAPE), whereas the ML parcel is based on the mean temperature and mixing ratio in the lowest $150 \mathrm{hPa}$. The CONV parcel reflects the surface temperature required for free convection based on the surface mixing ratio. The condensation level for each of these parcels is compared in the analyses below.

\section{The Bald Fire}

The Bald Fire $\left(40.9^{\circ} \mathrm{N}, 121.3^{\circ} \mathrm{W}\right)$ was started by lightning late on 31 July 2014. It was one of several lightning ignited fires in northern California and southern Oregon, including the adjacent Eiler Fire. The fire growth patterns on 1 and 2 August, determined from nightly US Forest Service airborne infrared sensing (http://nirops.fs.fed.us/), are shown in Fig. 3. Based on these data, the fire consumed 7275 ha of mixed conifer forest during its first day, and by the end of the subsequent day had burned an additional 6821 ha. The weather conditions on both days featured afternoon high temperatures near $30^{\circ} \mathrm{C}$, relative humidity of $\sim 15 \%$ and west winds gusting up to $6 \mathrm{~m} \mathrm{~s}^{-1}$.

During its rapid expansion on 2 August, the Bald Fire developed a towering pyroCu that subsequently matured into a pyroCb. Visible satellite data show the pyroCu initiation occurred at 13:30 PDT, with continued cloud growth through mid-afternoon (Fig. 4a-d). At 14:26 PDT the MODIS-Aqua satellite recorded a detailed image of the growing pyroCu, showing crisp cumuliform cloud features above the fire perimeter with more diffuse cloud elements extending to the northeast (Fig. 4e). The spreading cloud features were detrained from the primary updraft and then advected in southwesterly flow aloft.

The total FRP from the Bald Fire at the time of the MODIS-Aqua image was $19700 \mathrm{MW}$ summed over 30 fire pixels. The pixel maximum was $2258 \mathrm{MW}$, though the py- 


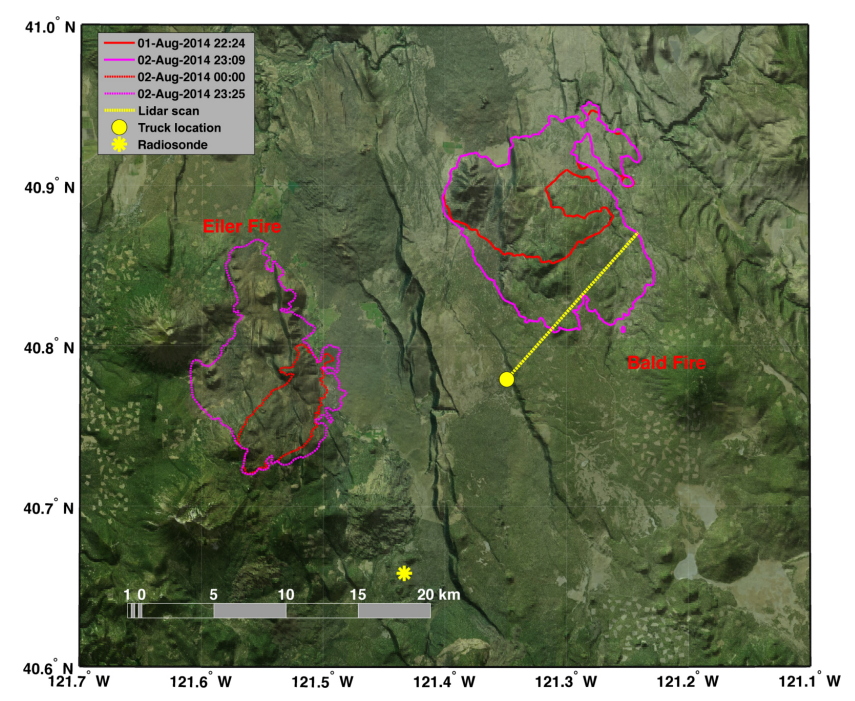

Figure 3. Bald and Eiler Fire progression map for 1 and 2 August. The fire perimeters are from the US National Forest Service National Infrared Operations (NIROPS) flights. The background is a satellite image draped over the terrain, which is highlighted with hill shading. Also shown are the truck location (yellow dot), lidar scan path (yellow line), and radiosonde location (yellow star).

roCu obscures a substantial portion of the fire. For comparison, the earlier MODIS-Terra overpass at 12:45 PDT yielded a maximum FRP of just $829 \mathrm{MW}$ and a total FRP of 3836 MW summed over 13 fire pixels. Clearly the fire experienced a rapid change in size and intensity during the early afternoon, coincident with the development of the pyroCu.

\subsection{Lidar observations}

The truck-mounted Doppler lidar was situated $\sim 7 \mathrm{~km}$ southwest of the fire where it conducted RHI scans of the windward edge of the developing pyroCu from 13:50 to 15:32 PDT on 2 August. During this time, 95 RHI scans were completed, providing a time- and space-resolved measure of the plume evolution, including the height of the condensation level. The lidar location relative to the fire perimeter is indicated in Figs. 3 and 4e. Figure 4f provides photograph from the lidar vantage point showing the windward edge of the cloud capped smoke column.

Figure 5 shows a sequence of lidar scans spanning the 5 min period prior to the MODIS-Aqua overpass. These data are expressed as the logarithmic attenuated backscatter coefficient (hereafter backscatter) in units of $\mathrm{m}^{-1} \mathrm{sr}^{-1}$. Red and blue dots represent the leading plume edge and attenuation point, respectively, along each individual beam. The backscatter is due to smoke and debris in the lower portion of the plume (below $5500 \mathrm{~m}$ ) and due to cloud droplets in the pyroCu aloft. The laser beam attenuates in both the smoke and the cloud water, but the cloud edge is marked by a distinct increase in the backscatter and more rapid attenuation.
For example the distance between the leading plume edge (red dots) and the attenuation point (blue dots) tends to be much larger in the lower portion of the plume, whereas above $5500 \mathrm{~m}$ the attenuation occurs over just a few range gates. These aspects of the data give the pyroCu cloud returns a "crisper" edge.

While pyroCus were already present at the beginning of the scan sequence, the data show the development of a new cloud element. Figure 5a and b for example, show only a few points of rapid attenuation and high backscatter aloft, whereas starting at Fig. 5c a new, upright cloud edge is detected. This nascent pyroCu element then rapidly expands during the subsequent RHI scans, reaching a height of at least $8500 \mathrm{~m}$ before moving out of the lidar field of view (Fig. $5 \mathrm{~d}-$ f). As we show in the radar analysis below, the actual plume top was as high as $12 \mathrm{~km}$ in the $10 \mathrm{~min}$ following these scans.

The scans, which were roughly parallel to the mean wind direction, also reveal that the plume experienced significant variations in tilt with time, alternating between windward (Fig. 5a) and rearward sloping geometries (Fig. 5f). In fact, the windward protrusion of the plume was as much as $2 \mathrm{~km}$ away from its base. Large coherent vortices are also apparent along the plume edge, especially in Fig. 5a and b as the "stair step" pattern in the plume edge detections. Based on the radial velocity data (not shown) the inward clefts in the plume edge correspond to enhanced flow into the plume and outward lobes reflecting flow towards the lidar. Vortices of this sort are a well-known feature of rising thermals and plumes and play a leading role in entrainment (Scorer, 1957; Woodward, 1959).

Following the initial plume rise, sustained pyroCus were observed with the lidar until 15:32 PDT, at which point the truck was relocated for safety reasons. To determine the plume condensation level, we aggregate data from all of the lidar scans during this period. From this larger data sample, Fig. 6a presents the time-maximum backscatter as a function of height and distance, and Fig. 6b as a function of height only. In addition, Fig. $6 \mathrm{c}$ shows the computed percentiles $(5,50$, and 95 th percentiles) of the attenuation depth binned into $100 \mathrm{~m}$ intervals. Collectively, these data reinforce many of the aspects of the initial plume rise sequence discussed above. For example, there is a persistent transition in backscatter near $5500 \mathrm{~m}$ (blue line in Fig. 6a and b). Below this level, the backscatter approximately linearly decreases with height, consistent with the entrainment of clear air into an aerosol-laden plume. In contrast, at $5500 \mathrm{~m}$ the backscatter sharply increases (as does the SNR, not shown), corresponding to the condensation level and development of the pyroCu. The backscatter intensity remains high there and above due to the continued presence of liquid water.

The attenuation depth also shows a sharp transition at $5500 \mathrm{~m}$ (Fig. 6c). Below that level the median attenuation depth increases with height, which is again consistent with the dilution of the smoke plume via entrainment. At $5500 \mathrm{~m}$ the attenuation depth (across all percentiles) sharply de- 

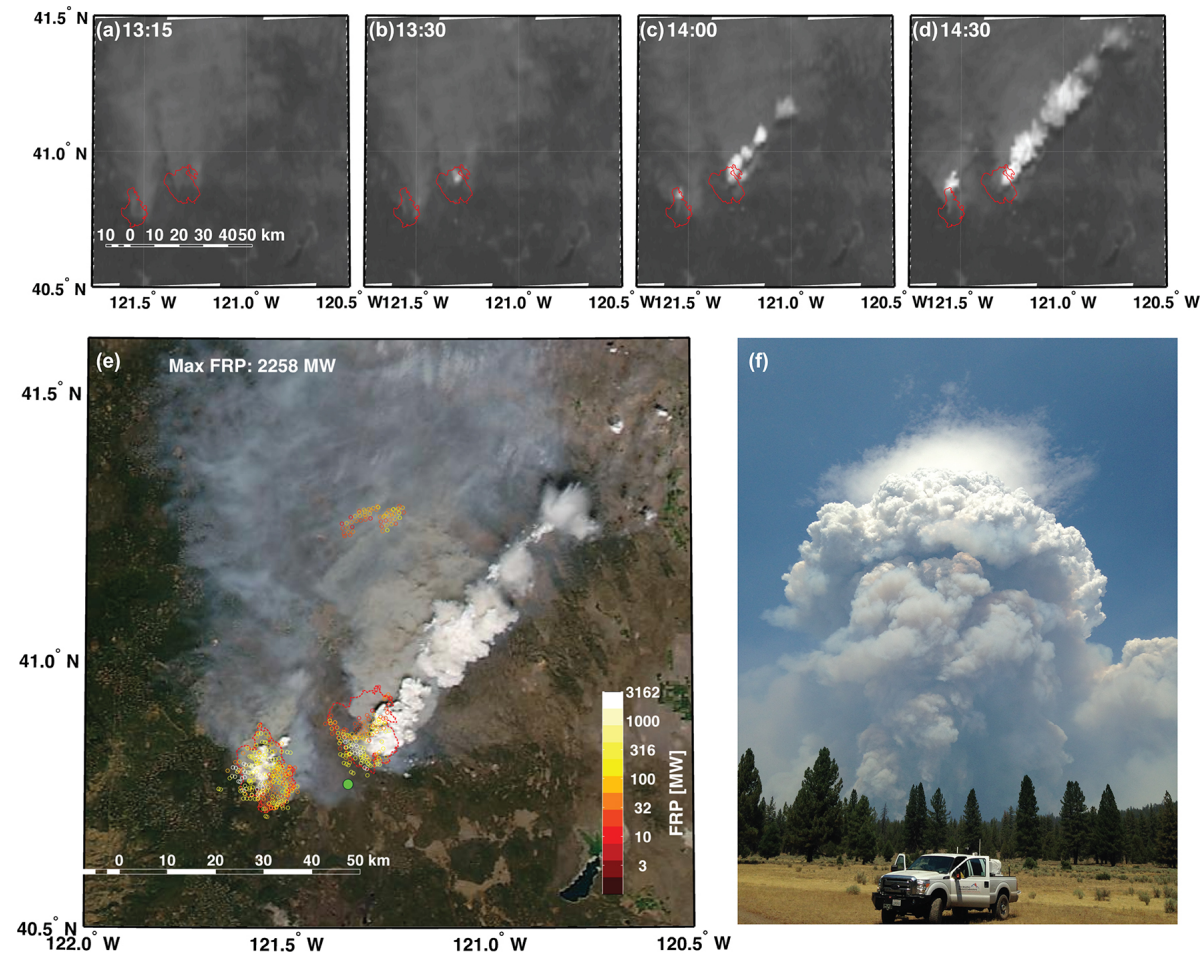

Figure 4. Overview of the pyrocumulus initiation and growth on 2 August 2014. (a-d) GOES-15 visible imagery showing the pyroCu initiation. (e) MODIS-Aqua visible image at 14:26 PDT along with fire-radiative power (FRP, colored circles). (f) Photograph of the lidar vantage point and the windward edge of convective column and pyroCu at 14:01 PDT. The truck location is indicated in as a green dot in (e). The fire perimeters are as in Fig. 3.
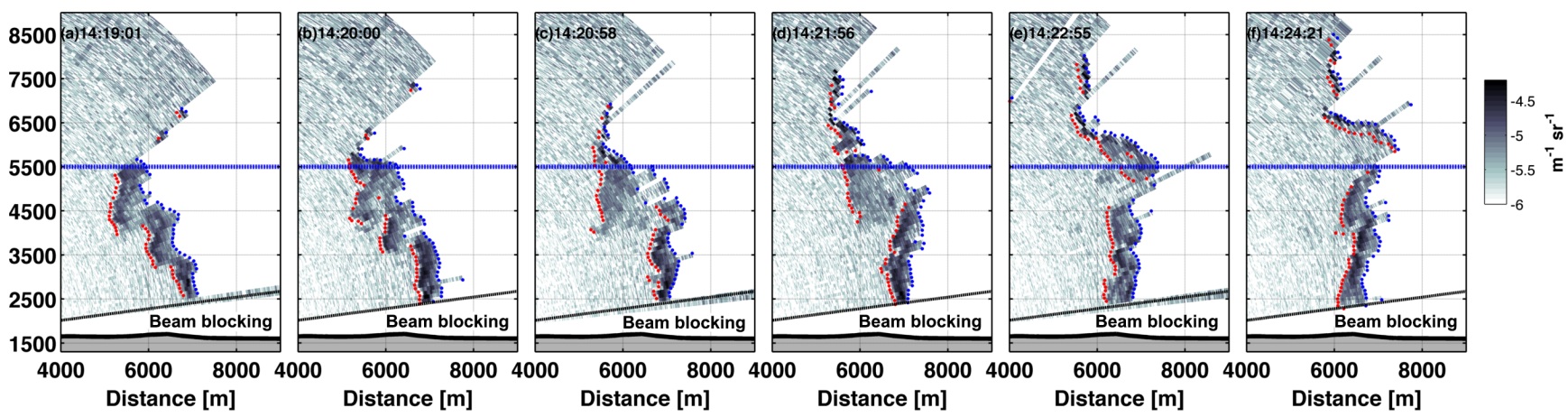

Figure 5. Plume rise sequence recorded by successive lidar RHI scans from 14:19 to 14:24 PDT. The displayed data are the logarithmic attenuated backscatter coefficient $\left(\mathrm{m}^{-1} \mathrm{sr}^{-1}\right)$. The plume edge and attenuation points are shown in red and blue dots, respectively. Data beyond the attenuation point is shadowed (blank points). The dashed blue line indicates the condensation level.

creases, converging towards a median value of $\sim 200 \mathrm{~m}$. The rapid attenuation aloft is consistent with the presence of liquid water drops and supports our interpretation that the change in backscatter intensity is due to condensation in the plume. From these data, we therefore conclude that the observed condensation level occurs very near $5500 \mathrm{~m}$ and was nearly constant throughout the $1.5 \mathrm{~h}$ observation period despite many changes in fire intensity.

\subsection{Radar analysis}

Since the pyroCu cloud tops exceeded the lidar range, the maximum smoke injection depth is obtained from the radar echo tops product from the NWS radar in Medford, OR (KMAX), which is $\sim 200 \mathrm{~km}$ to the northwest. Figure $7 \mathrm{a}$ shows the time maximum of the echo tops above the Bald Fire on 2 August. These data indicate that smoke reached altitudes in excess of $12 \mathrm{~km}$, and thus the convective column rose an additional $3.5 \mathrm{~km}$ above the maximum height 

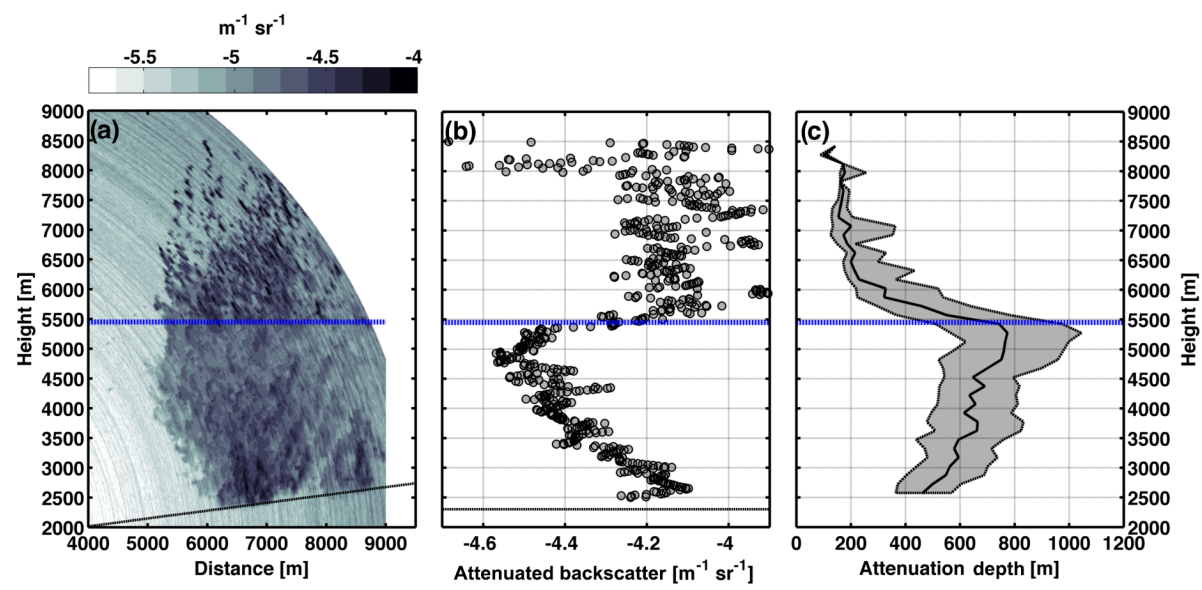

Figure 6. Statistical analysis of lidar data between 13:50 and 15:02 PDT showing the plume condensation level. (a) Maximum backscatter as a function of height and distance. (b) Maximum backscatter as a function of height only. (c) 5, 50, and 95th percentiles of the attenuation depth as a function of height. The dashed blue line indicates the inferred condensation level.

resolved in the lidar scans. The radar returns also show that the highest echo tops occur in a localized region above the fire perimeter where pyroCus were most prevalent. In contrast, the smoke layers without pyroCus correspond to plume heights closer to $6 \mathrm{~km}$.

An additional interesting aspect of the radar data is the presence of deep echo tops southwest (e.g., upwind) of the infrared fire perimeter (solid contours, Fig. 7a). This observation is consistent with the periodic forward tilt of the plume as observed in the lidar backscatter (Figs. 5 and 6). We hypothesize that the forward tilt relates to large-scale vortices that form as the plume penetrates through a stable layer at the top of the boundary layer (Saunders, 1962), and due to the deflection of the ambient flow around the plume.

Figure $7 \mathrm{~b}$ shows the corresponding time series of the maximum radar echo tops. The pyroCu initiation at 13:30 PDT, as shown in Fig. 4b, corresponds to a rapid rise in echo tops from 6500 to $10000 \mathrm{~m}$. Following the initial plume growth, the plume tops slowly rise until 14:20 PDT at which point a second period of rapid plume growth occurs, pushing the convective column to heights above $12 \mathrm{~km}$. The onset of this deep plume penetration closely corresponds to the lidar plume rise sequence shown in Fig. 6, as well as the MODISaqua image. The plume heights subsequently subside, remaining near $10 \mathrm{~km}$ for the balance of the afternoon before diminishing more substantively at night.

A 3-D volume rendering of radar reflectivity from the Bald Fire at the time of maximum injection height (14:29 PDT) reveals additional aspects of the plume structure (Fig. 7c). The isosurfaces for $30,28,26,24$, and $18 \mathrm{dbZ}$ are shown, along with the fire perimeters (red shading), lidar scan plane (black dots), lidar plume edge detections (yellow dots), and the lidar-derived condensation level (green contour). These volume data show an expansive region of high reflectivity immediately above the fire perimeter. The reflectivity and plume height diminish towards the northeast, consistent with the fall out of the larger soot and ash particles in the downwind direction (e.g., southwest flow aloft). We note that since the radar is not sensitive to cloud droplets or micron-sized smoke, it is possible that the cloud edges and some smoke reside outside of the radar volume rendering. It is also clear from these data that the lidar sees only the leading edge of the plume before attenuating in dense smoke and cloud water, consistent with the analyses presented above.

The shape of particles within the plume can be inferred by considering the differential reflectivity $\left(Z_{\mathrm{dr}}\right)$ from the Medford, OR radar at different heights (Fig. 8). Three elevation angles are inspected $\left(0.5,1.5\right.$, and $\left.2.4^{\circ}\right)$, intersecting the updraft core at heights of 4115,7742 , and $11009 \mathrm{~m}$, respectively. The lowest scan shows very high $Z_{\mathrm{dr}}$, indicative of large, horizontally oriented particles, which is consistent with ash (Melnikov et al., 2008, 2009; Lang et al., 2014) (Fig. 8a). In contrast, the mid-elevation scan intersects the plume above the condensation level and shows a significant reduction in $Z_{\mathrm{dr}}$, with values between 0 and 2.5 in the updraft core (Fig. 8b). These values correspond to more spherical particles and small ice, suggesting the presence of large hydrometeors. Finally the upper-most portion of the plume, at $\sim 11 \mathrm{~km}$, exhibits negative $Z_{\mathrm{dr}}$, presenting the possibility of vertically oriented graupel particles (Fig. 8c).

\subsection{Thermodynamic analysis}

The lidar-observed condensation level and radar-estimated plume tops provide valuable constraints on the plume structure when contextualized with atmospheric profiles collected adjacent to the fire. Figure 9a, for example, shows data from a radiosonde launched at 21:00 PDT from $\sim 15 \mathrm{~km}$ to the southwest of the fire (location shown in Fig. 3).

The sounding shows that the afternoon CBL extends from the surface $(1364 \mathrm{~m})$ to $\sim 4000 \mathrm{~m}$ and is capped by a pro- 

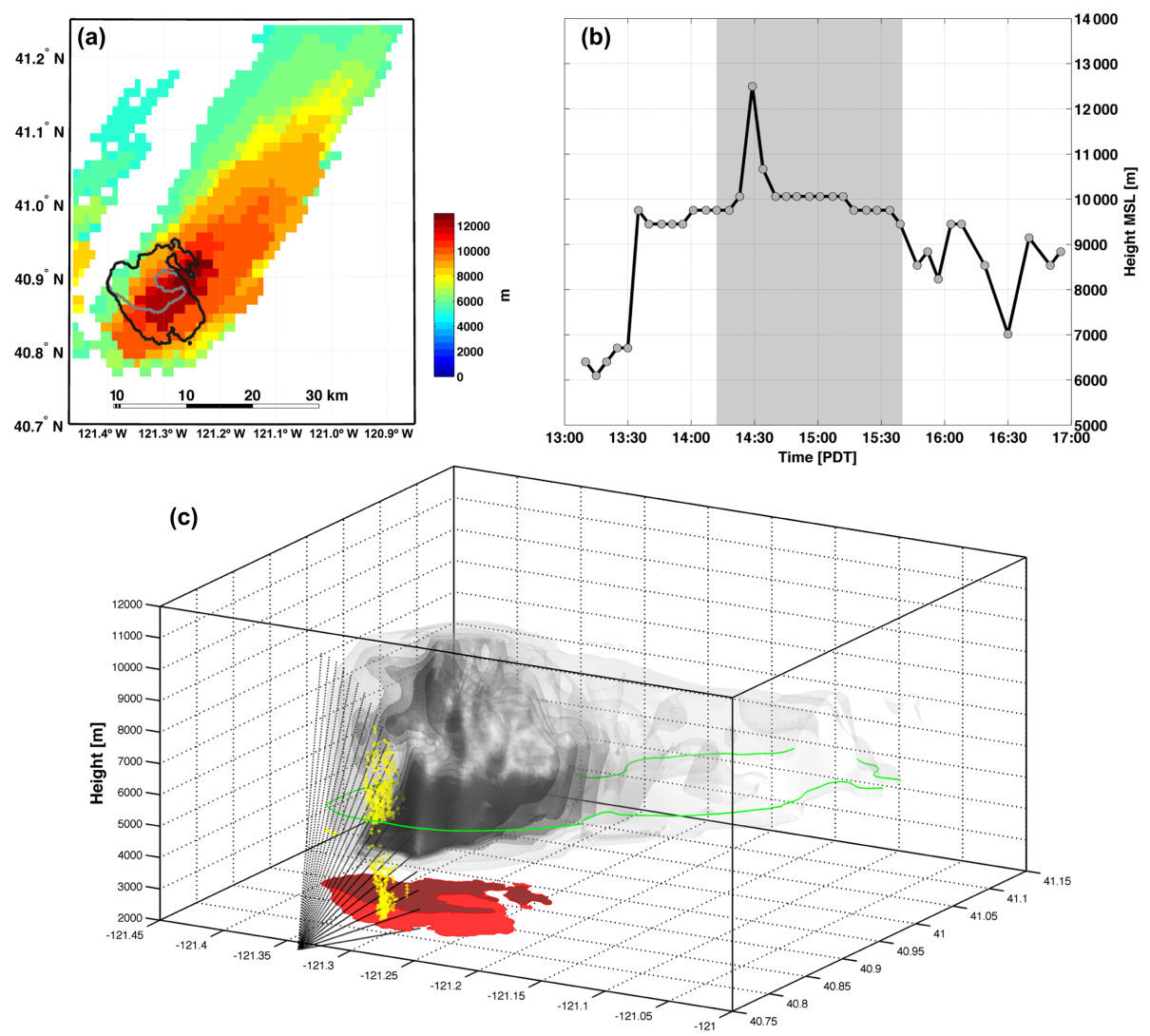

Figure 7. Radar analysis of the Bald Fire convective column. (a) Maximum echo top heights (color shading) during the Bald Fire along with the NIROPS fire perimeters (gray and black contours). (b) Time series of the maximum echo tops heights. Gray shading shows the period of lidar observations. (c) Volume rendering of the Bald Fire plume at 14:29 PDT. Reflectivity isosurfaces are displayed at 30, 28, 26, 24, 22 and $18 \mathrm{dbZ}$. The lidar scan path and plume detections are shown in black and yellow dots, respectively. Fire perimeters are shown in red shading. The lidar-derived condensation level is indicated by the green contour.
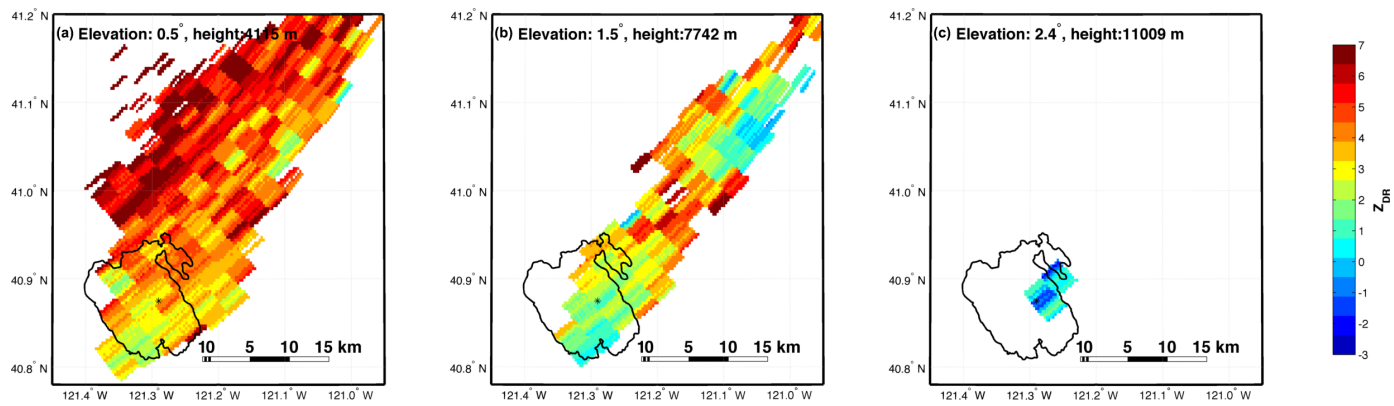

Figure 8. Differential reflectivity $\left(Z_{\mathrm{dr}}\right)$ analysis of the Bald Fire plume at 14:29 PDT. (a-c) $Z_{\mathrm{dr}}$ at the $0.5,1.5$, and $2.4^{\circ}$ elevation sweeps. The black contour shows the fire perimeter on 2 August.

nounced stable layer. Within the CBL, the water vapor mixing ratio is roughly constant at $\sim 5 \mathrm{~g} \mathrm{~kg}^{-1}$, whereas above the CBL, a layer of very dry air is observed with a mixing ratio of only $\sim 0.5 \mathrm{~g} \mathrm{~kg}^{-1}$. Further aloft, near $400 \mathrm{hPa}$, a layer of higher humidity air, reflecting monsoonal moisture, is found. The height of the tropopause is $\sim 13 \mathrm{~km}$.

Relative to the observed profile, the "in cloud" profile is estimated by pseudo-adiabatically lifting a parcel from the lidar-observed condensation level at $5500 \mathrm{~m}$. The resulting parcel possesses $910 \mathrm{~J} \mathrm{~kg}^{-1}$ of CAPE, which is an upper bound on the energy available for buoyant ascent. The equilibrium level (EL) of the pyroCu parcel is $11742 \mathrm{~m}$, which is in close agreement with the radar-estimated echo tops, but does not account for the inertial overshoot of the parcel, which is likely reflected in the localized region of radar plume heights exceeding $12 \mathrm{~km}$ (Fig. 7a). 

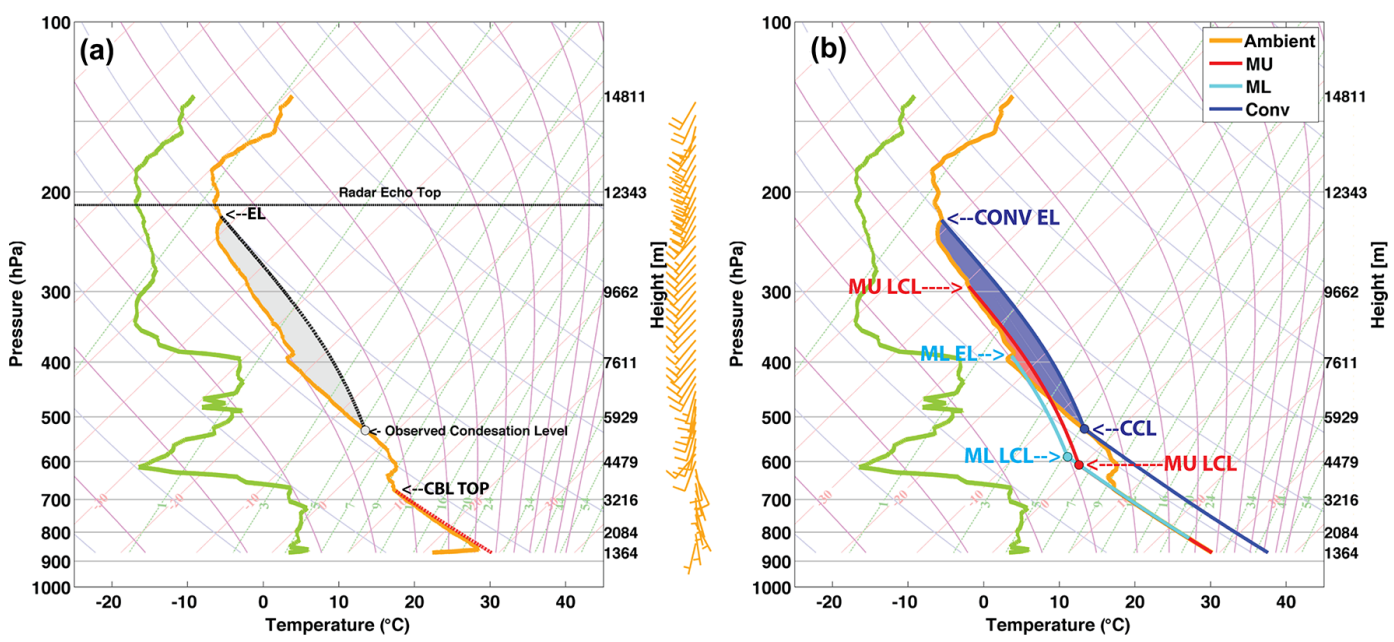

Figure 9. Thermodynamic analysis of the ambient environment and plume parcels. (a) Observed sounding from 2 August 2014, 21:00 PDT showing the adjusted boundary layer profile (dashed red line), the lidar-derived condensation level (gray circle), the moist-adiabatic ascent from the condensation level, equilibrium level, and the radar-derived echo tops. (b) Analysis of lifted parcels, showing the most unstable (MU), mixed-layer (ML), and convective (CONV) parcel trajectories. The condensation and equilibrium levels for each parcel are shown, and their CAPE is shaded.

Also of note, the homogeneous freezing level $\left(-38^{\circ} \mathrm{C}\right)$ in the plume profile occurs at $10,158 \mathrm{~m}$ and the temperature at the $\mathrm{EL}$ is $-52{ }^{\circ} \mathrm{C}$, indicating that the upper portion of the cloud must be glaciated. As such, this particular pyroconvective cloud should be classified as a pyroCb. In fact, pyroCbs from other nearby fires on that day were known to produce lightning as well as a significant and destructive fire-whirl (Muller and Herbster, 2014).

\section{Lifted parcels}

One of the main goals of this paper is to compare the observed plume properties with conventional estimates of condensational level and convective potential. To that end, in this subsection we consider each of the three lifted parcels described in Sect. 2.4 as representations of the observed plume. The parcel ascents are shown in Fig. 9b.

In this case, the MU parcel (red line, Fig. 9b) originates in the CBL and produces an LCL of $4367 \mathrm{~m}$, which is more than $1 \mathrm{~km}$ lower than the lidar-observed condensation level. In addition, compared to the observed plume structure, the MU parcel possesses minimal CAPE and must overcome appreciable convective inhibition (CIN) before reaching its level of free convection. Similarly, the ML parcel encounters its LCL at $4641 \mathrm{~m}$, possesses almost no CAPE, and also must overcome appreciable CIN (cyan line, Fig. 9b). The LCL for the ML parcel is higher than that of the MU parcel because the layer averaged mixing ratio is less than the maximum mixing ratio in the CBL.

Interestingly, the CONV parcel provides the best representation of the observed plume (dark blue line, Fig. 9b). In this case the surface mixing ratio is $5.2 \mathrm{~g} \mathrm{~kg}^{-1}$ and the corresponding convective condensation level (CCL) is found at $5549 \mathrm{~m}$, which is very close to the lidar-derived $5500 \mathrm{~m}$. Commensurately, the EL and CAPE for the CONV parcel are also close to the observed values. The convective temperature, which is the surface temperature that must be reached to support convection, is $36.4^{\circ} \mathrm{C}$. The high temperature for the day was $29^{\circ} \mathrm{C}$, making surface based convection extremely unlikely outside of the fire modified environment.

From these analyses it is clear that the plume condensation level is substantively higher than the ambient LCL, supporting the results of Luderer et al. (2006, 2009). Further, using the CCL, not the LCL, and assuming that the fire readily exceeds the convective temperature, provides the best representation of the plume condensation level in this case. This is a potentially useful diagnostic for forecasters and fire managers. It should be noted, however, that the CONV parcel, and its associated dry-adiabat up to the CCL (dark blue line, Fig. 9b), does necessarily reflect the actual properties of the lower plume. Rather, the plume must be superadiabatic near its base, cooling largely due to entrainment as it decays towards adiabatic ascent further aloft (Emanuel, 1994; Trentmann et al., 2006; Freitas et al., 2007).

\section{The Rocky Fire}

The Rocky Fire $\left(38.9^{\circ} \mathrm{N}, 122.5^{\circ} \mathrm{W}\right)$ started late on 29 July 2015 (cause unknown) in the coastal range of northern California and burned in complex terrain through fuels consisting of grass, brush, and conifers (Figs. 1 and 10). The US Forest Service NIROPS fire perimeters show that the fire burned 3356 ha during the first day, and then consumed another 3153 ha on 30 July, the day of our observations. The fire growth on the 30 July was complex, expanding along multi- 


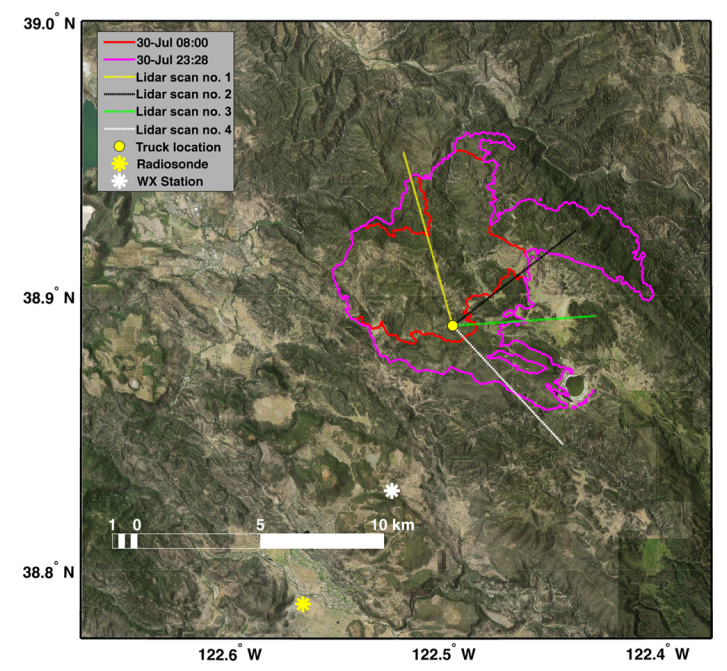

Figure 10. Rocky Fire progression map for 30 July 2015. The fire perimeters are from the US National Forest Service National Infrared Operations (NIROPS) flights. The background is a satellite image draped over the terrain, which is indicated with hill shading. Also shown are the truck location (yellow dot), lidar scan paths (colored lines), radiosonde location (yellow star), and weather station location (white star).

ple flanks (Fig. 10). Notably the first day's fire growth, while rapid, did not generate pyroCus, whereas the second day did (Fig. 11). In addition, compared to the long-lived Bald Fire pyroCu/Cb, the Rocky Fire plumes were transient, repeatedly forming and dissipating in rapid succession. In this section we examine the structure of these transient pyroCu along with the environmental conditions affecting their evolution.

\subsection{Lidar observations}

Lidar RHI scans where conducted between 15:45 and 20:08 PDT from an already burned area within the Rocky Fire perimeter (Fig. 10). This location allowed for scans of four separate pyroCu plumes rising from the complex fire perimeter. A total of $267 \mathrm{RHI}$ scans were performed.

PyroCu were first observed with the lidar starting at $\sim 16: 00$ PDT rising from the northwest flank of the fire $\left(319^{\circ}\right.$ azimuth, scan path \#1 in Fig. 10). Figure 12 shows a sequence of photographs (top panels) and contemporaneous lidar scans (bottom panels) detailing the onset and expansion of this cloud-topped plume. The plume was initially observed as it penetrated through a stable layer at the top of the CBL, evident as a lateral smoke layer at $2600 \mathrm{~m}$ in the backscatter data and as a diffuse haze in the photographs. During this time, a thin pileus cloud accompanied the developing pyroCu and the lidar cloud returns were limited to a few points near the plume top (Fig. 12f).

By 16:03 PDT, however, a distinct cumuliform cloud had developed (Fig. 12b) and the lidar backscatter showed a commensurate increase in intensity and attenuation along the py-
roCu edge (Fig. 12g). Based on these data the cloud base was at $\sim 4200 \mathrm{~m}$. The subsequent scans show the rapid pyroCu development, and by 16:09 PDT cloud edges were detected as high as $7500 \mathrm{~m}$. Interestingly, soon thereafter the pyroCu detrained from the convective column and dissipated (not shown).

Another pyroCu event at 18:00 PDT is detailed in Fig. 13 corresponding to a lidar azimuth of $86^{\circ}$ (scan path \#3 in Fig. 11). This plume initiated $\sim 2.5 \mathrm{~km}$ east of the lidar location. As in the previous case, the rapidly growing plume was first recorded as it rose through the boundary layer top, now at $\sim 2300 \mathrm{~m}$, and expanded into the free troposphere (Fig. 13a and e). Subsequent scans revealed the onset of pyroCu with a condensation level of $4200 \mathrm{~m}$, which is unchanged from the earlier Rocky Fire pyroCu event detailed in Fig. 12. In this case, however, the cloud top was not as well documented because attenuation at the cloud base shielded the lidar view of the upper plume.

The photographs detailing the plume rise show changes in smoke color near the base of the convective column (Fig. 13a-d). For example, at 18:05 PDT the smoke is a dark gray (Fig. 13a), whereas later the smoke is increasingly white (Fig. 13d). We believe the change in smoke coloration is associated with changes in the completeness of combustion: flaming combustion produces smoke dominated by black carbon aerosols, whereas smoldering combustion generates more organic carbon aerosol, which more effectively backscatter sunlight and appear whiter (Bellouin, 2014; Saleh et al., 2014).

An additional aspect of the observed plume rise is the relationship between the updraft strength and the ambient wind. This relationship is examined in Fig. 14, which displays VAD wind profiles (Fig. 14a and b) and RHI radial velocities detailing the plume structure (Fig. 14c-e). The wind profiles show significant shear over the lowest $2 \mathrm{~km}$ of the atmosphere. Strong $\left(5-7 \mathrm{~m} \mathrm{~s}^{-1}\right)$ northwesterly winds near the surface transition to weak flow at the boundary layer top $\left(0-1 \mathrm{~m} \mathrm{~s}^{-1}\right.$ near $\left.2300 \mathrm{~m}\right)$, then reverse to easterly flow aloft (Fig. 14a and b). The observed near-surface wind speed maximum is atypical in the atmospheric boundary layer and "adverse" wind profiles of this character have previously been linked to blow-up fires (Byram, 1954).

Compared to the ambient wind, the flow within the plume is characterized by much stronger velocities (Fig. 14c and d). For example, outbound speeds in excess of $15 \mathrm{~m} \mathrm{~s}^{-1}$ are recorded at numerous locations within the plume at 18:09 PDT. The actual updraft speed likely exceeds these values since the radial velocity data only reflect the projection of the updraft onto the oblique lidar beam. Significant downdrafts are also observed in the upper portion of the plume, especially at 18:13 PDT (blue shading, Fig. 14c and d).

The RHI velocity data also show that the strength of the updraft diminished with time. For example, comparative histograms demonstrate that strong outbound velocities were both higher and more common at 18:09 than 18:13 PDT 

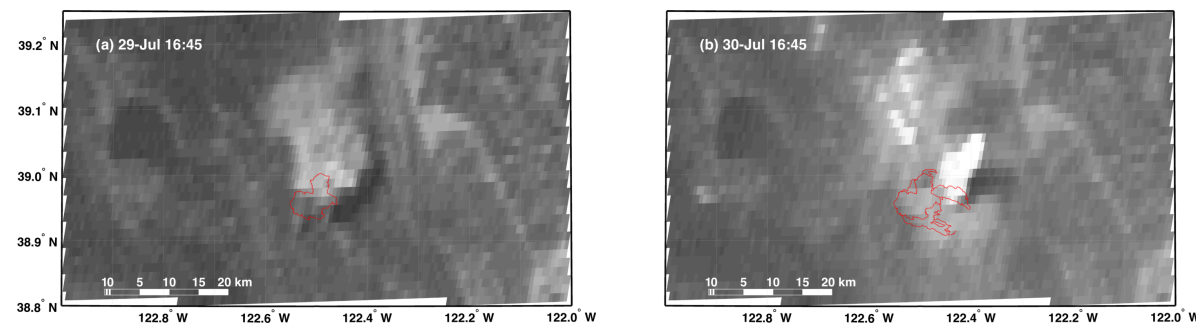

Figure 11. Visible satellite (GOES-15) images showing the difference in the Rocky Fire plume between 16:45 PDT on 29 and 30 July. The data show a pyroCu tower on 30 July that is absent on 29 July.
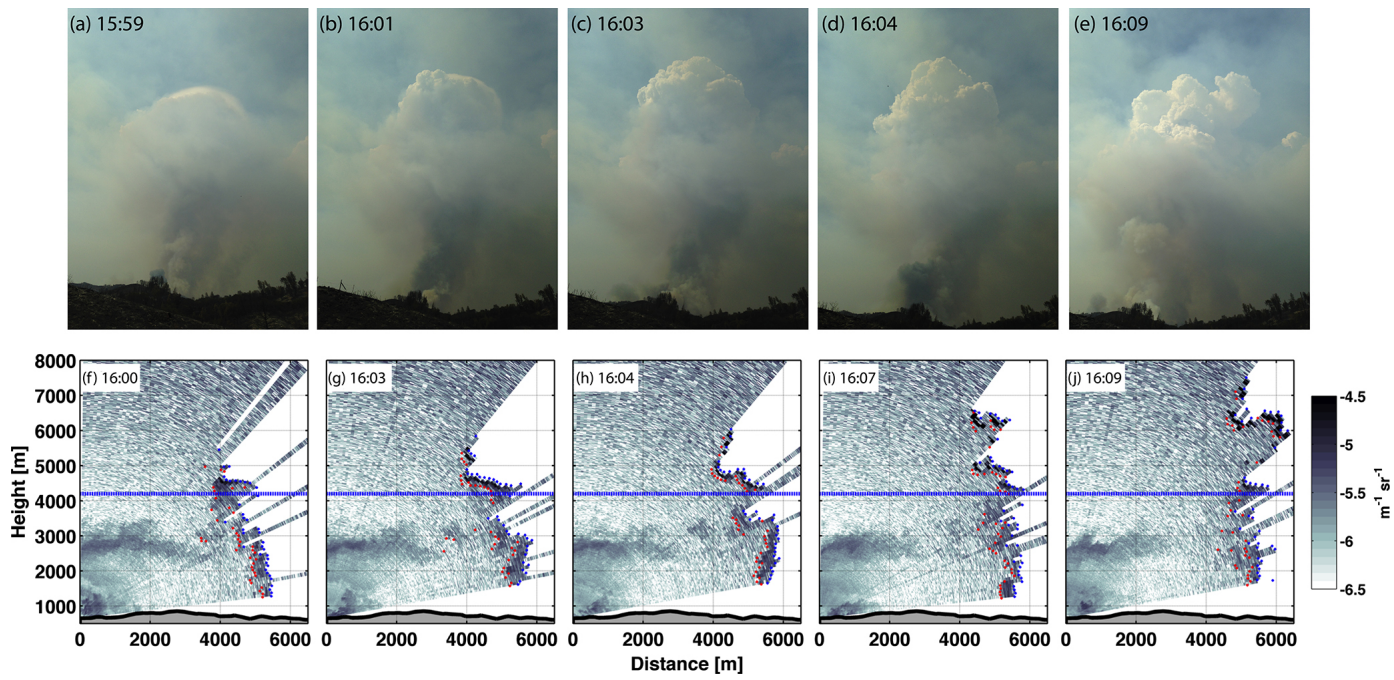

Figure 12. Pyrocumulus development from 15:59-16:09 PDT on 30 July 2015. (a-e) Photographs of the plume rise and pyroCu development. (f-j) Lidar backscatter showing the onset of condensation and subsequent cloud growth. The dashed blue lines shows the lidar-derived condensation level.

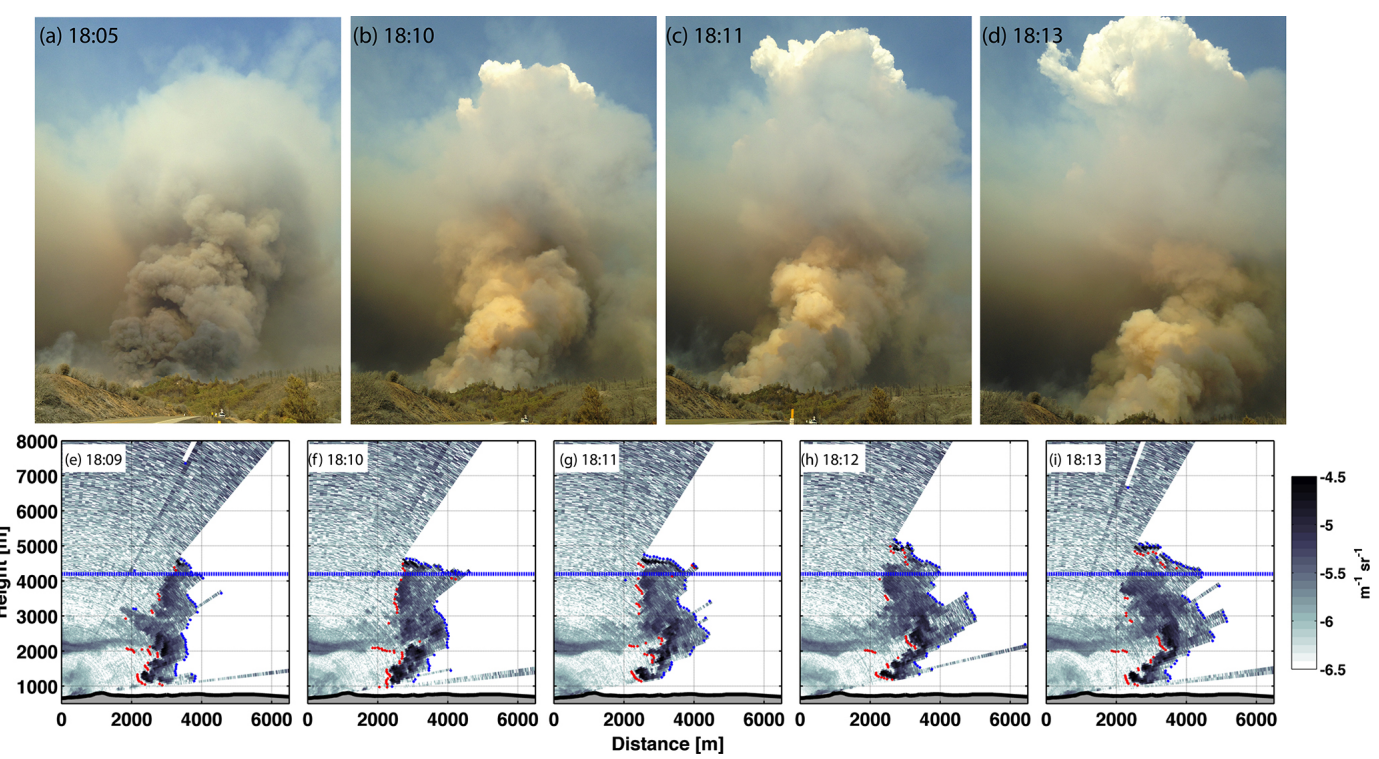

Figure 13. Pyrocumulus development from 18:05-18:13 PDT on 30 July 2015. (a-d) Photographs of the plume rise and pyroCu development. (e-i) Lidar backscatter showing the onset of condensation and subsequent cloud growth. The dashed blue lines shows the lidar-derived condensation level. 

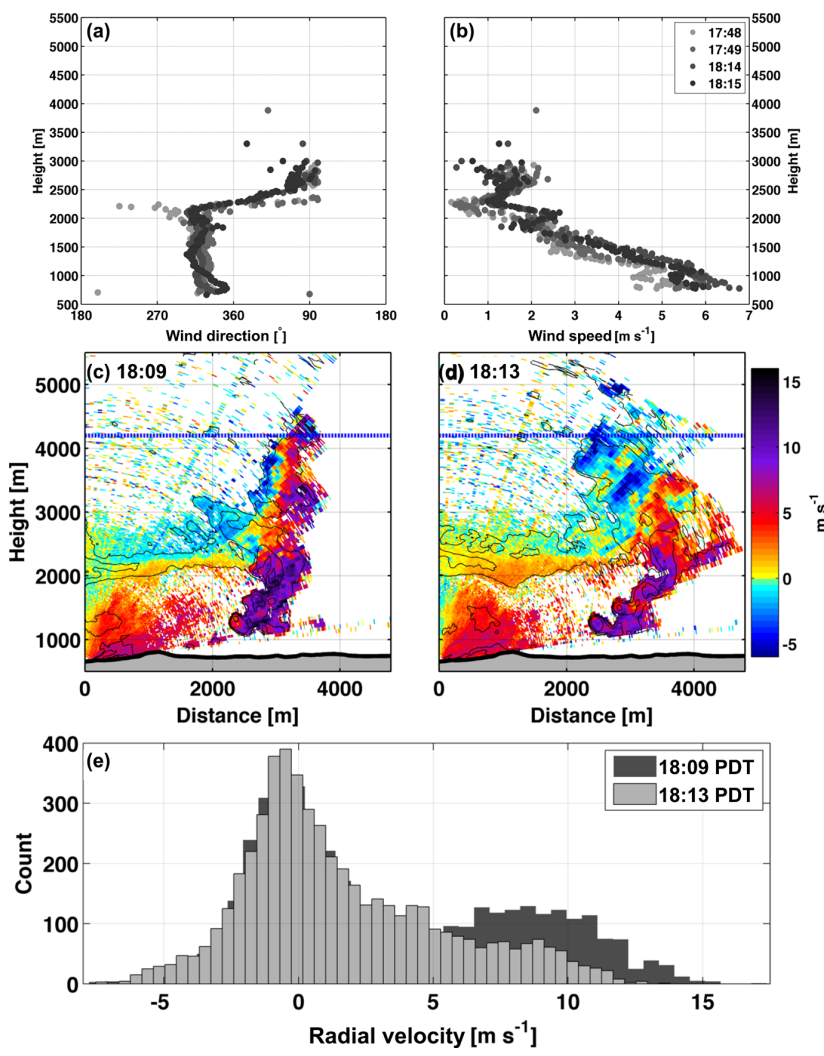

Figure 14. Analysis of the interaction of the plume with the ambient wind. (a-b) VAD-derived profiles of the ambient wind speed and direction. (c-d) Radial velocities during the plume rise and smoke backscatter (black contours). (e) Comparative histogram of radial velocities at 18:09 and 18:13 PDT.

(Fig. 14e). This observation is consistent with the change in smoke coloration described above: flaming combustion is likely to produce stronger updrafts due to more rapid heat release.

Changes in plume geometry also accompany the reduction in updraft strength. The plume is at first mostly upright (Fig. 14c) and later becomes more sheared (Fig. 14d). Specifically, the leading plume edge becomes tilted downwind within the boundary layer, while the upper portion of the plume bends back towards the observing location. Based on these data, we hypothesize that as the fire's updraft weakens, it becomes more susceptible to the ambient shear. The role of wind shear as a limiting factor in plume development is further discussed below.

A more robust examination of the plume condensation level during the Rocky Fire's multiple pyroCu events is presented in Fig. 15. These analyses leverage the aggregated data from all of the RHI scans on 30 July. Unsurprisingly, the time-maximum backscatter exhibit a sharp transition near $4200 \mathrm{~m}$ (Fig. 15a and b), as was indicated in the earlier plume rise sequences (Figs. 12 and 13). Below $4200 \mathrm{~m}$, the backscatter decays roughly linearly with height, and above that level the backscatter converges to a value of near $-4 \mathrm{~m}^{-1} \mathrm{sr}^{-1}$ (Fig. 15b). Likewise, the attenuation depth linearly increases from the surface up to $4200 \mathrm{~m}$, then abruptly decreases to a median depth of $\sim 200 \mathrm{~m}$. This pattern is consistent with the dilution of the smoke plume by entrainment and the onset of condensation aloft. Importantly, these analyses are remarkably similar to those during the Bald Fire suggesting a clear lidar signature of pyroCu onset. Moreover, the condensation level is once again found to be constant throughout the observing period, indicating that ambient atmospheric conditions rather than variations in water released during combustion likely control its height.

\subsection{Radar analysis}

Radar data are again used to estimate the maximum smoke injection depth. The Rocky Fire was within $\sim 100 \mathrm{~km}$ of both the Sacramento (KDAX) and Beale Air Force Base (KBBX) NWS radars (Fig. 1), and data from both sites are in agreement.

The maximum echo tops (from KDAX) occur between 7000 and $7500 \mathrm{~m}$, consistent with the lidar cloud detections (Fig. 16a). The spatial pattern of echo tops indicate that plumes of similar height developed on all of the expanding flanks of the fire. Interestingly, the corresponding time series demonstrates the plume transience, showing rapid variations in plume height throughout the late afternoon (Fig. 16b). Each spike corresponds to a short-lived pyroCu with durations ranging from $10-30 \mathrm{~min}$. Satellite data confirm the episodic nature of these plumes (not shown).

The variability in echo tops is also due to the presence of multiple updrafts. For example, a volume rendering of the reflectivity data at 16:09 PDT shows the two distinct updrafts associated with the complex fire perimeter (Fig. 16c). The narrow updraft rising from the northwestern flank of the fire is the same plume shown in Fig. 12, and the lidar plume detections agree well with the radar data (yellow dots, Fig. 16c). A second broader plume rises from the north and northeastern flanks of the fire at the same time. Above $5000 \mathrm{~m}$ the upper portions of both plumes are tilted to the north-northwest due to southeasterly flow in that layer. Later in the fire's evolution the plume growth shifted towards the east and southeast (not shown).

\subsection{Thermodynamic analysis}

The Rocky Fire pyroCu development is interesting in that the thermodynamic environment theoretically supports much deeper convection than was observed. Using radiosonde data from $\sim 15 \mathrm{~km}$ southwest of the fire at 21:05 PDT, Fig. 17a shows that moist adiabatic ascent from the observed $4200 \mathrm{~m}$ cloud base would generate $2035 \mathrm{~J} \mathrm{~kg}^{-1}$ of CAPE and that the plume equilibrium level would be $\sim 13 \mathrm{~km}$, impinging on the tropopause. The radar and lidar data indicate, however, that the plumes ascended to no higher than $\sim 7.5 \mathrm{~km}$, corre- 

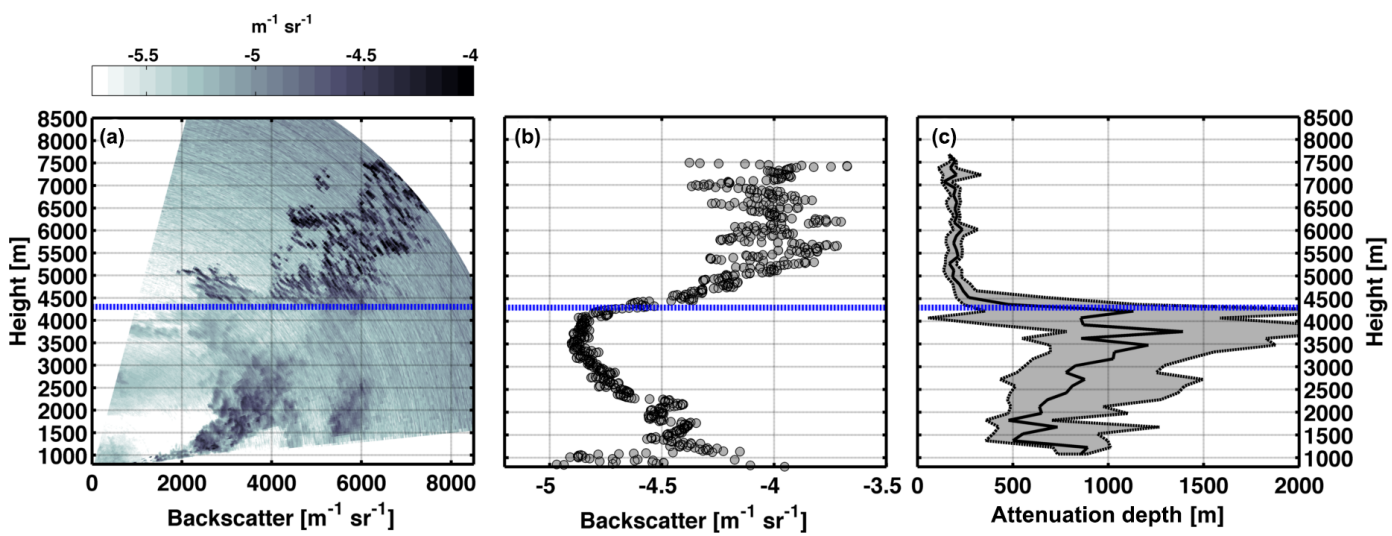

Figure 15. Statistical analysis of lidar data between 15:45 and 20:08 PDT on 30 July 2015. (a) Maximum backscatter as a function of height and distance. (b) Maximum backscatter as a function of height only. (c) 5, 50, and 95th percentiles of the attenuation depth as a function of height. The dashed blue line indicates the inferred condensation level.
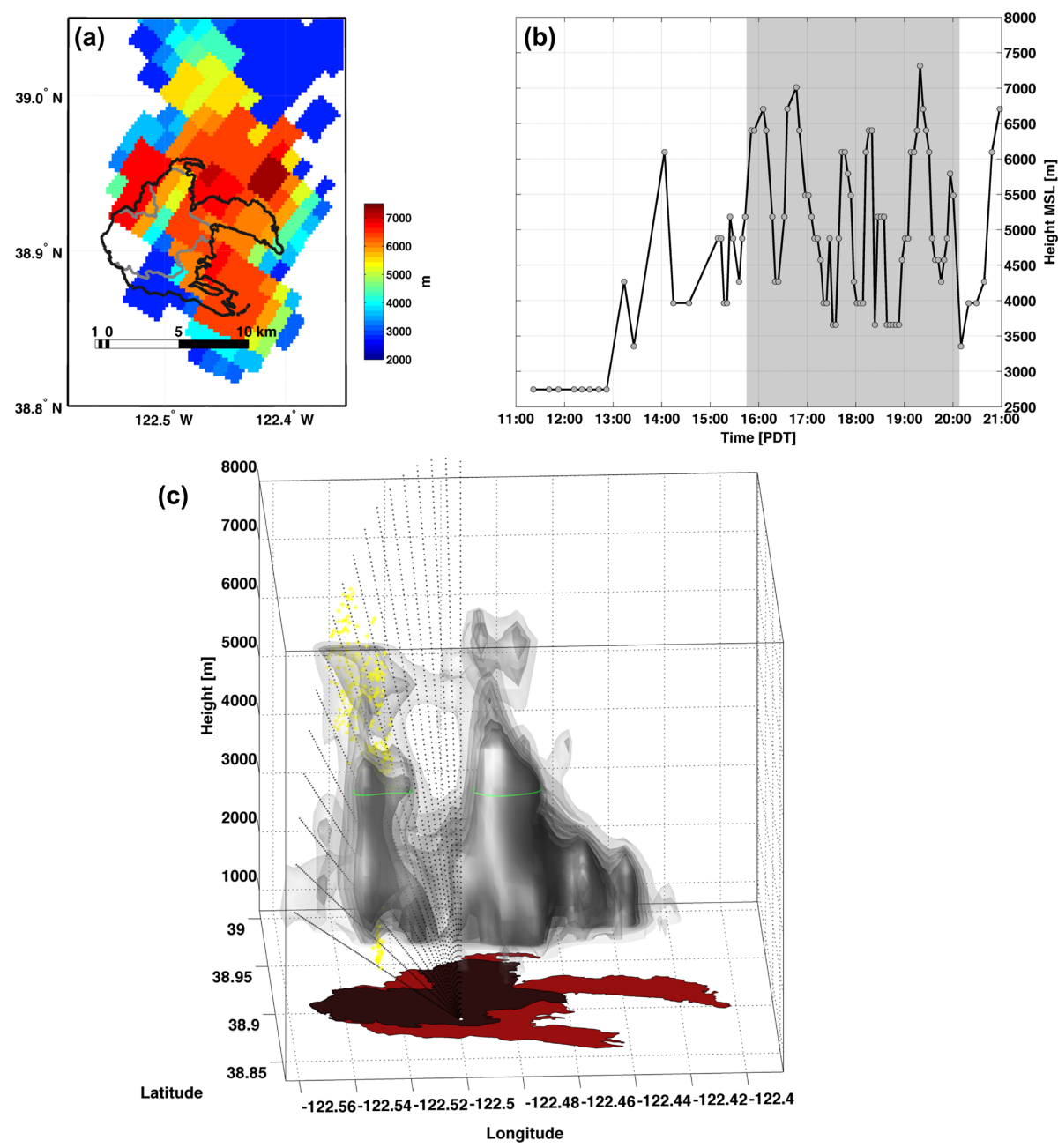

Figure 16. Radar analysis of the Rocky Fire convective column. (a) Maximum echo top heights (color shading) along with the NIROPS fire perimeters (gray and black contours). (b) Time series of the maximum echo tops heights. Gray shading shows the period of lidar observations. (c) Volume rendering of the Rocky Fire plume at 16:09 PDT. Reflectivity isosurfaces are displayed at 30, 28, 26, 24, 22 and 18 dbZ. The lidar scan path and plume detections are shown in black and yellow dots, respectively. Fire perimeters are shown in red shading. 

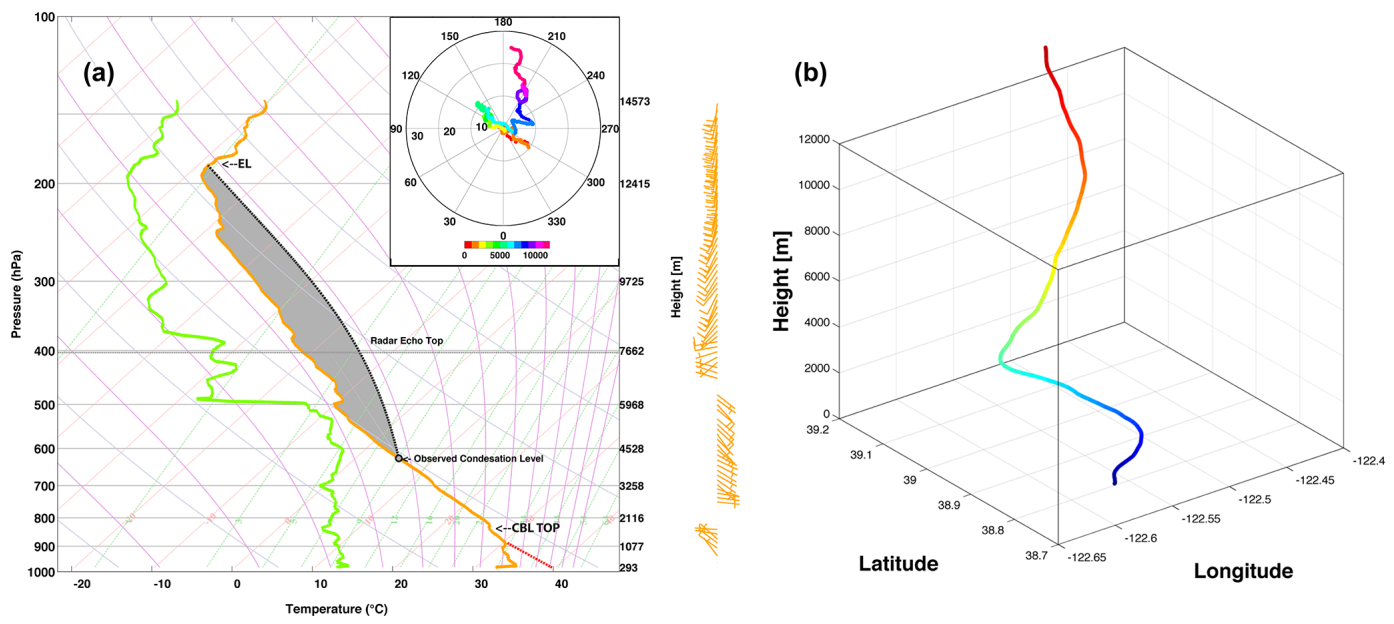

Figure 17. Thermodynamic analysis of the ambient environment during the Rocky Fire. (a) Observed sounding from 21:05 PDT showing the adjusted boundary layer profile (dashed red line), the lidar-derived condensation level (gray circle), the moist-adiabatic ascent from the condensation level, and the radar-derived echo tops. The inset is a hodograph and the wind barbs on the right indicate how the wind speed and direction change with height. (b) Balloon ascent path showing the affect of wind shear on a buoyant parcel.

sponding to plume top temperature of $-20^{\circ} \mathrm{C}$. As such, these clouds are best classified as pyroCu, and never developed as deep pyroCb.

What then limits the growth? There appear to be two related limiting factors in the plume rise: (1) wind shear, and (2) dry air entrainment. The lidar wind profiles, presented above in Fig. 14, indicate significant wind shear between the CBL and free troposphere. This wind shear is also apparent in the radiosonde wind profile, which shows a $180^{\circ}$ wind shift at $2300 \mathrm{~m}$ (wind barbs and hodograph Fig. 17a). The flow below this level is from the west-northwest, whereas the flow above, and extending up to $\sim 7 \mathrm{~km}$, is from the eastsoutheast. The layer of southeasterly flow is associated with a surge of monsoonal moisture.

A second layer of significant wind shear at $7000 \mathrm{~m}$ separates the monsoon flow from southwesterly flow in the upper troposphere. This shear also coincides with a rapid decrease in dew point temperature, and thus relative humidity. It is notable then that the maximum echo tops occur only about $500 \mathrm{~m}$ above the upper shear layer. Visual observations throughout the afternoon and early evening suggest this shear zone affected the pyroCu development, tending to sweep the upper portion of the cloud away from the updraft core. The detraining upper portions of the cloud subsequently developed ragged and wispy edges indicative of dry air entrainment as opposed to the crisp crenelations of growing cumulus congestus.

The effect of the wind shear on a buoyant parcel is easily visualized by examining the ascent track of the radiosonde, which rose at a mean rate of $2.7 \mathrm{~m} \mathrm{~s}^{-1}$ (Fig. 17b). The ambient shear causes a pronounced zigzag pattern that is clearly detrimental to sustained upright convection despite the substantive CAPE. This result is not surprising in that CAPE is

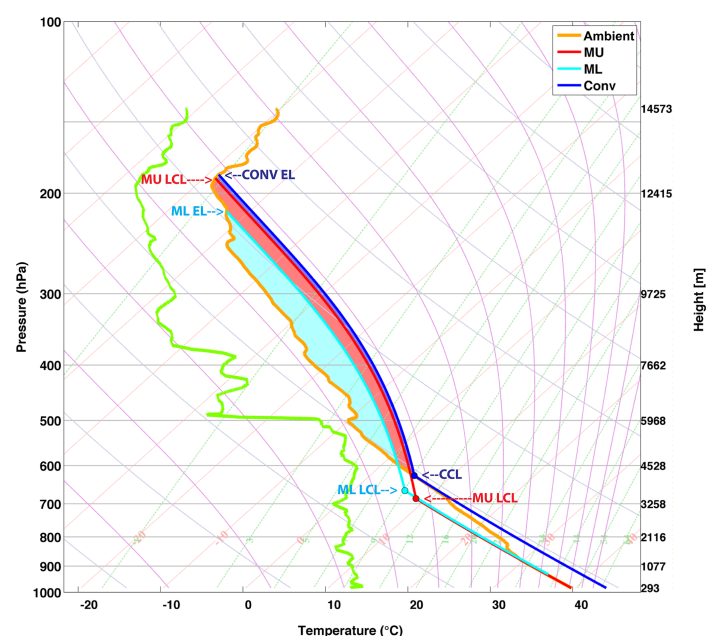

Figure 18. Analysis of lifted parcels, showing the most unstable (MU), mixed-layer (ML), and convective (Conv) parcel trajectories. The condensation levels and CAPE for each parcel is described in the text.

known to overestimate convective development and updraft strength (Markowski and Richardson, 2011).

\section{Lifted parcels}

Despite their limited vertical development, the Rocky Fire pyroCu provide additional support for the hypothesis that the plume condensation level occurs above the ambient LCL. Following the same procedures described for the Bald Fire we examine three convective parcels, the ascents of which are shown in Fig. 18. The LCLs for the MU and ML parcels are 3503 and $3768 \mathrm{~m}$, respectively (red and cyan lines, Fig. 18). Both of these lifted parcels must overcome modest CIN to 

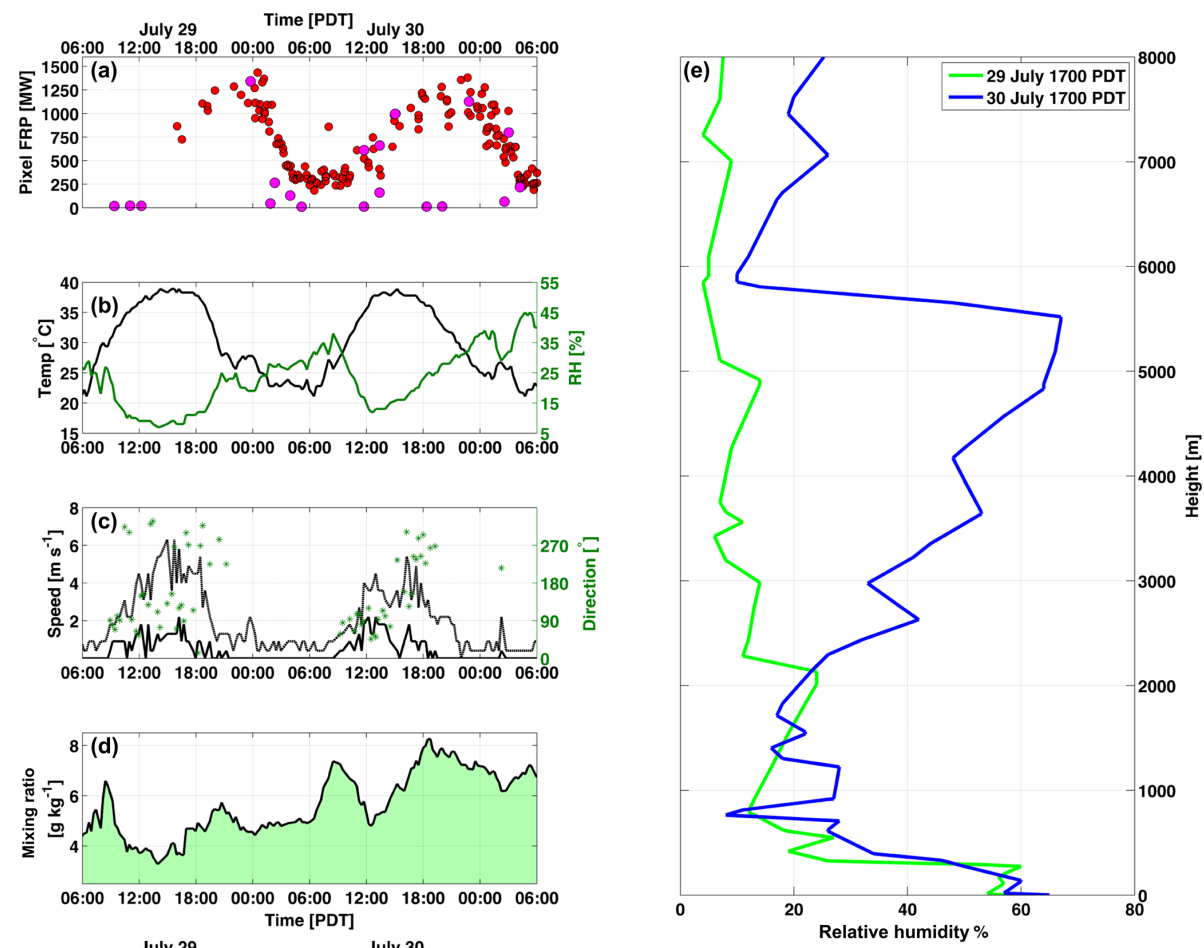

Figure 19. Analysis of the environmental conditions on 29 and 30 July. (a) Fire radiative power from GOES-15 (red dots) and MODIS (purple dots). (b) Temperature (black line) and relative humidity (green line) time series. (c) wind speed (black line), gust (dashed black line) and direction (green starts). (d) Surface mixing ratio. (e) Comparison of the vertical profile of relative humidity from the KOAK sounding at 17:00 PDT on 29 and 30 July. The location of the weather station is shown in Fig. 10.

reach their level of free convection. In contrast, the computed $\mathrm{CCL}$ of $4250 \mathrm{~m}$ is much closer to the lidar-observed condensation level at $\sim 4200 \mathrm{~m}$. The corresponding convective temperature is $\sim 43^{\circ} \mathrm{C}$, which is higher than the observed daytime temperature of $39^{\circ} \mathrm{C}$. These results, like those from the Bald Fire, again suggest that the CCL is a useful parameter for estimating pyroCu/Cb convective initiation heights.

\subsection{Fire radiative power and environmental moisture}

Figure 19a shows the GOES-15 and MODIS FRP in for the Rocky Fire on 29-30 July 2015. From these data it is clear that the diurnal cycle of fire intensity is similar during the first two days of fire growth, with peak FRP values near $1500 \mathrm{MW}$ in the late afternoon and fire activity extending into the late evening. Interestingly, despite comparable fire intensity, pyroCus were not observed on 29 July but were widespread on 30 July.

To better understand this disparity Fig. 19b-e compares the ambient meteorological conditions between days. These data are from a weather station just outside the fire perimeter, the location of which is shown in Fig. 10 (data obtained from MesoWest, Horel et al., 2002), and the 17:00 PDT upper air soundings at Oakland International Airport (KOAK, location shown in Fig. 1). The high temperature on both days was $\sim 39^{\circ} \mathrm{C}$ and afternoon winds were from the west with peak gusts near $6 \mathrm{~m} \mathrm{~s}^{-1}$. The relative humidity was higher on 30 July than 29 July.

Figure 19d and e show the time series of the water vapor mixing ratio and the differences in the relative humidity from the KOAK soundings for two afternoons. From these data it is apparent that the onset of pyroCus on 30 July corresponds to the arrival of much higher humidity air, both at the surface and aloft. For example, the mixing ratio increases from 4.5 to $8 \mathrm{~g} \mathrm{~kg}^{-1}$ while the relative humidity at $5500 \mathrm{~m}$ jumps from 7 to $66 \%$. The corresponding change in the CCL is substantial, dropping from $5848 \mathrm{~m}$ on 29 July to $4267 \mathrm{~m}$ on 30 July. Since the fire intensity was similar on both afternoons it is likely that reduction in the height of CCL due to the influx of monsoon moisture was the driving factor in pyroCu formation. These observations support the conclusions of Luderer et al. $(2006,2009)$ that environmental moisture, not water released in combustion, is the primary control on pyroCu development.

\section{Summary and conclusions}

The observations presented in this paper demonstrate that plume condensation levels can exceed the height of the ambient LCL, sometimes substantially. For example, during the Bald Fire the plume condensation level was more than $1 \mathrm{~km}$ 
higher than the environmental LCL. As such, we conclude that the LCL should not be used, as it has been, as a parameter for assessing pyroCu/Cb potential outside of the limiting case where the CCL and LCL coincide, which is to say that widespread convective clouds are possible. While our observational results span a limited portion of the parameter space, they nonetheless provide strong support for the modeling results of Luderer et al. $(2006,2009)$ and Trentman et al. (2006), and seemingly contradict the results of Potter (2005).

While the CCL and the corresponding moist adiabatic ascent provide a useful approximation for plume properties, other factors must also be considered. Specifically, CAPE alone cannot determine the convective outcome. Our results from the Rocky Fire show, for example, that ambient wind shear and dry air entrainment can significantly curtail the convective development even in an environment that might otherwise support deep pyroCb. In addition, our results show that the change in environmental humidity, often in the form of a monsoonal surge, exerts a significant influence over the onset of pyroCus/Cbs by raising or lowering the height of $\mathrm{CCL}$. These results suggest that the moisture release during combustion is of secondary importance, at least in these observed cases.

While our results mark an advance in understanding py$\mathrm{roCu} / \mathrm{Cb}$ development, there is a clear need for new measurement and modeling investigations of pyroconvective clouds. Future field campaigns should include observations of the ambient environment (e.g., radiosondes, CBL properties), the lower plume structure (temperature, moisture, and momentum fluxes), and cloud properties (e.g., liquid and ice water path, particle size distributions, etc.). These data should subsequently inform physical fluid dynamical models in order to investigate aspects of plume dynamics that may not be observable. Some potential avenues for obtaining these observations include dropsondes from aircraft, surface and aircraft based dual-polarization radars, unmanned aerial vehicles, and dual-Doppler lidar deployed during large-scale prescribed burn experiments where the fuel loading and extent of combustion is known or can be determined after the fact.

Author contributions. C. B. Clements conceived of the field program, N. P. Lareau and C. B. Clements conducted the field measurements, and N. P. Lareau led the data analysis and writing.

Acknowledgements. The lidar and radiosonde data are available upon request from the authors. All other data sources are publicly available. This research is supported under grant AGS-1151930 from the National Science Foundation. Christopher C. Camacho contributed to the field observations during the Rocky Fire.

Edited by: P. Chuang

\section{References}

American Meteorological Society: Pyrocumulus, Glossary of Meteorology, available at: http://glossary.ametsoc.org/wiki/ Pyrocumulus (last access: October 2015), 2015a.

American Meteorological Society: Pyrocumulonimbus, Glossary of Meteorology, available at: http://glossary.ametsoc.org/wiki/ Pyrocumulonimbus (last access: October 2015), 2015b.

Banta, R. M., Olivier, L. D., Holloway, E. T., Kropfli, R. A., Bartram, B. W., Cupp, R. E., and Post, M. J.: Smoke-column observations from two forest fires using Doppler lidar and Doppler radar, J. Appl. Meteorol., 31, 1328-1349, doi:10.1175/15200450(1992)031<1328:SCOFTF>2.0.CO;2, 1992.

Bellouin, N.: Aerosols: The colour of smoke, Nat. Geosci., 7, 619620, doi:10.1038/ngeo2226, 2014.

Browning, K. A. and Wexler, R.: The determination of kinematic properties of a wind field using Doppler radar, J. Appl. Meteorol., 7, 105-113, doi:10.1175/15200450(1968)007<0105:TDOKPO>2.0.CO;2, 1968.

Byram, G. M.: Atmospheric conditions related to blowup fires, Sta. Pap. 35, US Department of Agriculture, Forest Service, Southeastern Forest Experiment Station, Asheville, NC, 1-30, 1954.

Charland, A. M. and Clements, C. B.: Kinematic structure of a wildland fire plume observed by Doppler lidar, J. Geophys. Res., 118, 3200-3212, doi:10.1002/jgrd.50308, 2013.

Clements, C. B. and Oliphant, A. J.: The California State University mobile atmospheric profiling system: A facility for research and education in boundary layer meteorology, B. Am. Meteorol. Soc., 95, 1713-1724, doi:10.1175/BAMS-D-13-00179.1, 2014.

Clements, C. B., Potter, B. E., and Zhong, S.: In situ measurements of water vapor, heat and $\mathrm{CO}_{2}$ gluxes within a prescribed grass fire, Int. J. Wildland Fire, 15, 299-306, doi:10.1071/WF05101, 2006.

Clements, C. B., Zhong, S., Goodrick, S., Li, J., Bian, X., Potter, B. E., Heilman, W. E., Charney, J. J., Perna, R., Jang, M., Lee, D., Patel, M., Street, S., and Aumann, G.: Observing the dynamics of wildland grass fires: FireFlux- A field validation experiment, B. Am. Meteorol. Soc., 88, 1369-1382, doi:10.1175/BAMS-889-1369, 2007.

Cunningham, P. and Reeder, M. J.: Severe convective storms initiated by intense wildfires: Numerical simulations of pyroconvection and pyro-tornadogenesis, Geophys. Res. Lett., 36, L12812, doi:10.1029/2009GL039262, 2009.

Emanuel, K. A.: Atmospheric convection, Oxford University Press, Oxford, 580 pp., 1994.

Freitas, S. R., Longo, K. M., Chatfield, R., Latham, D., Silva Dias, M. A. F., Andreae, M. O., and Carvalho Jr., J. A.: Including the sub-grid scale plume rise of vegetation fires in low resolution atmospheric transport models, Atmos. Chem. Phys., 7, 3385-3398, doi:10.5194/acp-7-3385-2007, 2007.

Fromm, M., Tupper, A., Rosenfeld, D., Servranckx, R., and McRae, R.: Violent pyro-convective storm devastates Australia's capital and pollutes the stratosphere, Geophys. Res. Lett., 33, L05815, doi:10.1029/2005GL025161, 2006.

Fromm, M., Lindsey, D. T., Servranckx, R., Yue, G., Trickl, T., Sica, R., and Godin-Beekmann, S.: The untold story of pyrocumulonimbus, B. Am. Meteorol. Soc. 91, 1193-1209, doi:10.1175/2010BAMS3004.1, 2010. 
Fromm, M. D. and Servranckx, R.: Transport of forest fire smoke above the tropopause by supercell convection, Geophys. Res. Lett., 30, 1542, doi:10.1029/2002GL016820, 2003.

Hogan, R. J., Illingworth, A. J., O'connor, E. J., and Baptista, J. P. V.: Characteristics of mixed-phase clouds. II: A climatology from ground-based lidar, Q. J. Roy. Meteorol. Soc., 129, 2117-2134, doi:10.1256/qj.01.209, 2003.

Holzworth, G. C.: Estimates of mean maximum mixing depths in the contiguous United States, Mon. Weather Rev., 92, 235-242, doi:10.1175/1520-0493(1964)092<0235:EOMMMD>2.3.CO;2, 1964.

Horel, J., Splitt, M., Dunn, L., Pechmann, J., White, B., Ciliberti, C., Lazarus, S., Slemmer, J., Zaff, D., and Burks, J.: Mesowest: cooperative mesonets in the Western United States, B. Am. Meteorol. Soc., 83, 211-225, doi:10.1175/15200477(2002)083<0211:MCMITW>2.3.CO;2, 2002.

Hufford, G. L., Kelley, H. L., and Sparkman, W.: Use of realtime multisattelite and radar data to support fire management, Weather Forecast., 13, 592-605, doi:10.1175/15200434(1998)013<0592:UORTMA>2.0.CO;2, 1998

Jones, T. A. and Christopher, S. A.: Satellite and radar observations of the 9 April 2009 Texas and Oklahoma grassfires, B. Am. Meteorol. Soc., 91, 455-460, doi:10.1175/2009BAMS2919.1, 2010a.

Jones, T. A. and Christopher, S. A.: Satellite and radar remote sensing of southern plains grass fires: A case study, J. Appl. Meteorol., 49, 2133-2146, doi:10.1175/2010JAMC2472.1, 2010b.

Kavouras, I. G., Nikolich, G., Etyemezian, V., DuBois, D. W., King, J., and Shafer, D.: In situ observations of soil minerals and organic matter in the early phases of prescribed fires, J. Geophys. Res., 117, D12313, doi:10.1029/2011JD017420, 2012.

Kiefer, C. M., Clements, C. B., and Potter, B. E.: Application of a mini unmanned aircraft system for in situ monitoring of fire plume thermodynamic properties, J. Atmos. Ocean. Tech., 29, 309-315, doi:10.1175/JTECH-D-11-00112.1, 2012.

Koltunov, A., Ustin, S. L., and Prins, E. M.: On timeliness and accuracy of wildfire detection by the GOES WF-ABBA algorithm over California during the 2006 fire season, Remote Sens. Environ., 127, 194-209, doi:10.1016/j.rse.2012.09.001, 2012.

Kovalev, V. S., Newton, J., Wold, C., and Hao, W. M.: Simple algorithm to determine the near-edge smoke boundaries with scanning lidar, Appl. Optics, 44, 1761-1768, doi:10.1364/AO.44.001761, 2005.

Lakshmanan, V., Hondl, K., Potvin, C. K., and Preignitz, D.: An improved method for estimating radar echo-top height, Weather Forecast., 28, 481-488, doi:10.1175/WAF-D-12-00084.1, 2013.

Lang, T. J. and Rutledge, S. A.: Cloud-to-ground lightning downwind of the 2002 Hayman forest fire in Colorado, Geophys. Res. Lett., 33, L03804, doi:10.1029/2005GL024608, 2006.

Lang, T. J., Rutledge, S. A., Dolan, B., Krehbiel, P., Rison, W., and Lindsey, D. T.: Lightning in wildfire smoke plumes observed in Colorado during summer 2012, Mon. Weather Rev., 142, 489507, doi:10.1175/MWR-D-13-00184.1, 2014.

Lareau, N. P. and Clements, C. B.: Cold Smoke: smokeinduced density currents cause unexpected smoke transport near large wildfires, Atmos. Chem. Phys., 15, 11513-11520, doi:10.5194/acp-15-11513-2015, 2015.

Luderer, G., Trentmann, J., Winterrath, T., Textor, C., Herzog, M., Graf, H. F., and Andreae, M. O.: Modeling of biomass smoke injection into the lower stratosphere by a large forest fire
(Part II): sensitivity studies, Atmos. Chem. Phys., 6, 5261-5277, doi:10.5194/acp-6-5261-2006, 2006.

Luderer, G., Trentmann, J., and Andreae, M. O.: A new look at the role of fire-released moisture on the dynamics of atmospheric pyro-convection, Int. J. Wildland Fire, 18, 554-562, doi:10.1071/WF07035, 2009.

Markowski, P. and Richardson, Y.: Mesoscale Meteorology in Midlatitudes, John Wiley and Sons, Chichester, West Sussex, UK, 430 pp., 2011.

McRae, R. H., Sharples, J. J., Wilkes, S. R., and Walker, A.: An Australian pyro-tornadogenesis event, Nat. Hazards, 65, 18011811, doi:10.1007/s11069-012-0443-7, 2013.

Melnikov, V. M., Zrnic, D. S., Rabin, R. M., and Zhang, P.: Radar polarimetric signatures of fire plumes in Oklahoma, Geophys. Res. Lett., 35, L14815, doi:10.1029/2008GL034311, 2008.

Melnikov, V. M., Zrnic, D. S., and Rabin, R. M.: Polarimetric radar properties of smoke plumes: A model, J. Geophys. Res., 114, D21204, doi:10.1029/2009JD012647, 2009.

Muller, B. M. and Herbster, C. G.: Fire Whirls: Twisters That Light the Sky, Weatherwise, 67, 12-23, doi:10.1080/00431672.2014.960326, 2014.

Pahlow, M., Kleissl, J., Parlange, M. B., Ondov, J. M., and Harrison, D.: Atmospheric boundary-layer structure observed during a haze event due to forest-fire smoke, Bound.-Lay. Meteorol., 115, 53-70, doi:10.1007/s10546-004-6350-z, 2005.

Pearson, G., Davies, F., and Collier, C.: An analysis of the performance of the UFAM pulsed Doppler lidar for observing the boundary layer, J. Atmos. Ocean. Tech., 26, 240-250, doi:10.1175/2008JTECHA1128.1, 2009.

Peterson, D. A., Hyer, E. J., Campbell, J. R., Fromm, M. D., Hair, J. W., Butler, C. F., and Fenn, M. A.: The 2013 Rim Fire: Implications for predicting extreme fire spread, pyroconvection, and smoke emissions, B. Am. Meteorol. Soc., 96, 229-247, doi:10.1175/BAMS-D-14-00060.1, 2015.

Potter, B. E.: The role of released moisture in the atmospheric dynamics associated with wildland fires, Int. J. Wildland Fire, 14, 77-84, doi:10.1071/WF04045, 2005.

Radke, L. F., Lyons, J. H., Hobbs, P. V., Hegg, D. A., Sandberg, D. V., and Ward, D. E.: Airborne monitoring and smoke characterization of prescribed fires on forest lands in western Washington and Oregon, Tech. Rep. PNW-GTR-251, 81 For. Serv., US Dep. of Agric., Portland, Oregon, 81 pp., 1990.

Radke, L. F., Hegg, D. A., Hobbs, P. V., Nance, J. D., Lyons, J. H., Laursen, K. K., Weiss, R. E., Riggan, P. J., and Ward, D. E.: Particulate and trace gas emissions from large biomass fires in North America, in: Global Biomass Burning: Atmospheric, Climatic and Biospheric Implications, edited by: Levine, J. S., MIT Press, Cambridge, Massachusetts, 209-224, 1991.

Reid, J. S. and Hobbs, P. V.: Physical and optical properties of smoke from individual biomass fires in Brazil, J. Geophys. Res., 103, 32013-32031, 1998.

Reid, J. S., Koppmann, R., Eck, T. F., and Eleuterio, D. P.: A review of biomass burning emissions part II: intensive physical properties of biomass burning particles, Atmos. Chem. Phys., 5, 799825, doi:10.5194/acp-5-799-2005, 2005.

Rosenfeld, D., Fromm, M., Trentmann, J., Luderer, G., Andreae, M. O., and Servranckx, R.: The Chisholm firestorm: observed microstructure, precipitation and lightning activity 
of a pyro-cumulonimbus, Atmos. Chem. Phys., 7, 645-659, doi:10.5194/acp-7-645-2007, 2007.

Saleh, R., Robinson, E. S., Tkacik, D. S., Ahern, A. T., Liu, S., Aiken, A. C., and Donahue, N. M.: Brownness of organics in aerosols from biomass burning linked to their black carbon content, Nat. Geosci.,7, 647-650, doi:10.1038/ngeo2220, 2014.

Saunders, P. M.: Penetrative convection in stably stratified fluids, Tellus, 14, 177-194, doi:10.1111/j.2153-3490.1962.tb00130.x, 1962.

Scorer, R. S.: Experiments on convection of isolated masses of buoyant fluid, J. Fluid Mech., 2, 583-594, doi:10.1017/S0022112057000397, 1957.

Trentman, J., Luderer, G., Winterrath, T., Fromm, M. D., Servranckx, R., Textor, C., Herzog, M., Graf, H.-F., and Andreae, M. O.: Modeling of biomass smoke injection into the lower stratosphere by a large forest fire (Part I): reference simulation, Atmos. Chem. Phys., 6, 5247-5260, doi:10.5194/acp-65247-2006, 2006.
Winker, D., Vaughan, M. A., Omar, A., Hu, Y., Powell, K. A., Liu, Z., Hunt, W. H., and Young, S. A.: Overview of the CALIPSO mission and CALIOP data processing algorithms, J. Atmos. Ocean. Tech., 26, 2310-2323, doi:10.1175/2009JTECHA1281.1, 2009.

Woodward, B.: The motion in and around isolated thermals, Q. J. Roy. Meteorol. Soc., 85, 144-151, doi:10.1002/qj.49708536619, 1959.

Wooster, M. J.: Small-scale experimental testing of fire radiative energy for quantifying mass combusted in natural vegetation fires, Geophys. Res. Lett., 29, 2027, doi:10.1029/2002GL015487, 2002. 